CASTRO, Daniel; PIHUAVE, Pedro; PARRALES, Rosa; RAMÍREZ, Leticia; KARLO,

Jean: "El mapa de las víctimas. Pertinencia de los mapas cognitivos compuestos en el

análisis de la situación delictual a partir de un pequeño territorio"

Polit. Crim. Vol. 15, No 30 (Diciembre 2020), Art. 11, pp. 840-

[http://politcrim.com/wp-content/uploads/2020/12/Vol15N30A11.pdf]

\title{
El mapa de las víctimas. Pertinencia de los mapas cognitivos compuestos en el análisis de la situación delictual a partir de un pequeño territorio
}

The map of the victims. Pertinence of the Composed Cognitive Maps in the analysis of the criminal situation from a small territory perspective

\author{
Daniel Castro Aniyar \\ $\mathrm{PhD}$ Universidad Complutense de Madrid, Master EHESS-Paris \\ Miembro Director de Cendepeace, CIPSJ, Comisión de Investigación de Derecho, \\ Universidad Laica Eloy Alfaro (ULEAM) \\ daniel.castro@uleam.edu.ec \\ Pedro Pihuave \\ Magister Universidad Punta del Este-Universidad Laica Eloy Alfaro (ULEAM) \\ Fiscal del Estado. Profesor de la ULEAM \\ pedro.pihuave@uleam.edu.ec \\ Rosa Paula Parrales \\ Abogada \\ Investigadora de Cendepeace \\ e1313213116@uleam.edu.ec \\ Leticia Ramírez \\ Abogada \\ Investigadora de Cendepeace \\ abramirez@ozaetaabogados.com \\ Jean Karlo Moncayo \\ Estudiante de Derecho \\ Investigador de Cendepeace. ULEAM \\ e1316621471@uleam.edu.ec
}

\section{Resumen}

Se pondera el uso de Mapas Cognitivos Compuestos (MCC) como herramienta criminométrica en comparación con lasdenuncias administrativas y reportes policiale. Se aplicaron los MCC en el sub-circuito policial de la Playa el Murciélago del cantón Manta como ejemplo de un pequeño territorio según los datos por denuncias y reportes policiales del DAID (Departamento de Análisis e Información del Delito, adscrita a la Policía Nacional del Ecuador). Se demostró la pertinencia del instrumento como herramienta de medición del delito, y se discuten los beneficios que aporta a la policía de proximidad y a la sociedad en general. Se encontró que, a través de esta herramienta, se reconocen tipos de delitos ocultos a la estadística policial y prosecutorial, dinámicas espaciales del delito, como, problemas de 
defensibilidad así como coincidencias en la detección de situaciones y oportunidades delictivas que confirman, mejoran y sobre todo, trascienden el relato policial. Las políticas aplicadas desde el instrumento tuvieron un claro impacto positivo en la reducción y/o percepción del delito para el territorio, medible por denuncias administrativas y reportes policiales antes y después de la implementación de las políticas asociables al instrumento.

Palabras clave: mapas cognitivos compuestos; dinámica espacial del delito; situación delictiva; análisis del delito.

\begin{abstract}
This article contributes to the understanding of the Composite Cognitive Maps (MCC, in Spanish) as a criminometric tool comparing the data available of administrative complaints and police testimonies in Ecuador. The CCMs were applied in the police sub-circuit of Playa el Murciélago of the Manta canton as an example of a small conflict territory within Ecuador according to the data by prosecutorial reports and police reports of the DAID (Department of Crime Analysis and Information, attached to the National Police of Ecuador). We showed the CCM is a convenient tool for measuring crime. We discussed the benefits it brings to the local police and society in general. We could also recognize hidden crimes to police, some black figures and, in general, spatial dynamics of crime in a more detailed and comprehensive manner. The instrument had a clear positive impact on the reduction and perception of crime, measurable by administrative reports and police reports, before and after the implementation of the policies associated with it
\end{abstract}

Keywords: composed cognitive maps, spatial dynamics of crime, criminal situation, territorial analysis of crime.

\title{
Introducción: los Mapas Cognitivos Compuestos o MCC
}

Los Mapas Cognitivos Compuestos (en adelante "MCC") 1 son un instrumento diseñado con el fin de diagnosticar el análisis territorial del delito ${ }^{2}$ más adecuadamente a los fines de la criminología del lugar y el modelo del policiamiento o acción policial orientado a problemas $^{3}$, permitiendo el diseño de políticas públicas orientadas a la reducción del delito en zonas consideradas con alto riesgo de victimización a partir de mapas de territorialización. ${ }^{4}$ La investigación empírica disponible en este artículo revelará que los datos interterritoriales recolectados son más fidedignos y reales con base en la situación delictiva $^{5}$ que se obtiene mediante $\mathrm{MCC}$, que otros métodos criminométricos tradicionales

\footnotetext{
${ }^{1}$ CASTRO (2019b), pp. 1-23; CASTRO (2018b), passim; CASTRO (2018b), passim; BARCIA et al. (2018), passim; CASTRO y JÁCOME (2017a), pp. 192.

${ }^{2}$ FUNDACIÓN PAZ CIUDADANA (2012), p. 156.

${ }^{3}$ CENTER FOR PROBLEM- ORIENTED POLICING (2018), passim.

${ }^{4}$ TOLMAN (1948), p. 189; LYNCH (2015), pp. 204; KITCHIN (1996) p. 56-84; CASTRO (2005), passim; CASTRO y JÁCOME (2017b), passim.

${ }^{5}$ Situación delictiva es un concepto que permite coincidir la noción geertziana con la criminología de Clarke, en la que se entiende que la acción o emprendimiento delictivo corresponde a un conjunto denso de factores contextuales. CASTRO (2019b), p. 4.
} 
como el relato policial, la denuncia administrativa y las encuestas de victimización. ${ }^{6}$ Un producto resaltante de este instrumento es la denominada dinámica espacial del delito, el cual permite describir mecanismos de la oportunidad delictual en determinadas áreas territoriales y contrastarlas entre sí con el fin de revelar patrones complejos recurrentes sobre los cuales poder diseñar políticas criminales para grandes territorios o territorios mayores.

Los MCC benefician a los agentes policiales en sus investigaciones criminológicas permitiendo relativamente una mejor orientación en la identificación de patrones delictuales, situaciones y oportunidades delictivas, logrando tener una visión más amplia sobre la dimensión de los delitos cometidos en un área territorial. Esta estrategia parece tener la cualidad de poder fortalecer el servicio de proximidad policial, dadas las bases en que fue concebido, ${ }^{7}$ así como de sistematizar la observación de campo que realiza el agente o la agencia de seguridad en general.

Los MCC trabajan los patrones delictivos desde el ángulo territorial de Brantingham y Brantingham, en su teoría del patrón delictivo, la cual expresa que un patrón hace referencia al entorno físico, las pautas sociales y el comportamiento de las víctimas, haciendo que las oportunidades del delito aumenten. Los triángulos que incorporan víctimas y victimarios en este contexto contendrían un conjunto de factores que permiten al emprendedor delictivo efectuar con más facilidad el hecho delictivo. ${ }^{8}$

\section{Los MCC como herramienta de la policía de proximidad}

La policía de proximidad en el Estado ecuatoriano es un modelo policial comunitario, identificable con las siglas UPC (Unidades de Policía Comunitaria), UVC (Unidades de Vigilancia Comunitaria) y POLCO (Policía Comunitaria), que tiene como misión:

"construir una cultura de convivencia pacífica y de seguridad ciudadana en el barrio mediante acciones de carácter preventivo, proactivo y educativo con la finalidad de fomentar la participación ciudadana física y patriótica de las autoridades, organizaciones sociales y la comunidad". ${ }^{9}$

Sin embargo, es fundamental aclarar conceptualmente de cuál policía comunitaria se está hablando para esta noción. Los conceptos se han desplazado frecuentemente por el efecto de las demandas sociales y las redefiniciones oportunas en el mundo de la política. Ferret estudia este aspecto particular y agrega:

"La policía de proximidad es, pues, una traducción aleatoria de community policing. Esta forma doctrinaria designa, en realidad, prácticas policiales muy diferentes, que pueden ir desde una policía represiva en la modalidad de

\footnotetext{
${ }^{6}$ LOOR et al. (2019), passim.

${ }^{7}$ FRÜHLING (2003), passim; CASTRO et al. (2015), pp. 111-148; FERRET (2004), passim; PONTÓN (2009), passim.

${ }^{8}$ BRANTINGHAM y BRANTINGHAM (1993), pp. 261-264.

${ }^{9}$ POLICÍA NACIONAL (2012a), p.11
} 
«tolerancia cero» hasta una policía centrada alrededor de las técnicas de prevención y de relación con el público. Conviene tener en cuenta esta variedad de definiciones antes de iniciar cualquier evaluación del impacto potencial de una estrategia llamada de policía de proximidad sobre un territorio determinado". ${ }^{10}$

Dentro de las diferentes concepciones, que no son pertinentes para abordar en esta reflexión, es importante precisar dos opciones escogidas a los fines de la utilidad criminométrica del método en cuestión. En este sentido, cabe preguntarse si este modelo:

“¿significa hacer a la policía más accesible al ciudadano y más atenta a sus problemas? O tal vez, «acercar» reviste un sentido más sofisticado: el policía no solamente será un representante de la ley, sino un trabajador del saber y un especialista de su territorio el cual analizará de manera precisa para efectuar una política policial con otros colaboradores.". ${ }^{11}$

Esta pregunta no está abiertamente respondida en los documentos fundadores del Nuevo Modelo de Gestión Policial (o NMGP), el cual representa la reforma policial más exhaustiva y reciente en Ecuador ${ }^{12}$ ni en la doctrina ecuatoriana en la materia. Sin embargo, el Sistema David, CompStat policial de la Dirección de Análisis e Información del Delito (en adelante "DAID"), requiere progresivamente de este nivel de sofisticación de la función policial para el llenado de la data informática. ${ }^{13} \mathrm{De}$ tal modo que, en la práctica, la Policía ecuatoriana se ve presionada a especializarse en la materia criminológica y el análisis del delito desde el nivel más básico de la proximidad.

La filosofía de la proximidad pone particular énfasis en la prevención del crimen y, es por ello, que los MCC son una herramienta de mucho valor para poder identificar el nivel de criminalidad y violencia dentro de un territorio especifico, con fines de diseño de la política criminal. Como lo indica Ferret, "ello implica para el evaluador ir más allá de las representaciones clásicas, particularmente, las profesionales de la policía de proximidad". ${ }^{14}$

Los MCC dan a conocer dinámicas espaciales del crimen ${ }^{15}$, beneficiando no solo a la policía de proximidad (UPC) sino también a la sociedad en general, puesto que sus resultados, al ser integrales, hablan de la dinámica general de los territorios instrumentalizados. Este es un valor positivo común a todo programa de policía de proximidad, por la naturaleza misma de su trabajo:

\footnotetext{
${ }^{10}$ FERRET (2004), p. 180

${ }^{11}$ BRODEUR (2003), p. 206.

${ }^{12}$ POLICÍA NACIONAL (2012a), passim.

POLICÍA NACIONAL (2012b), passim.

PONTÓN (2009), passim.

${ }^{13}$ CASTRO et al. (2015), passim.

${ }^{14}$ FERRET (2004), p.181
}

${ }^{15}$ Se denomina dinámica espacial del delito o crimen al conjunto de patrones delictivos que son constantes interterritorialmente, de modo que faciliten el diseño de políticas públicas o criminales generales o dirigidas al macro nivel. CASTRO (2019b), p.9. 
"El éxito de un programa de policía de proximidad implica, por un lado, ir más allá de las declaraciones de intenciones y de los marcos difusos de las doctrinas que, con frecuencia, tienden a generalizar y, por el otro, favorecer la difusión de los conocimientos específicos de técnicas profesionales innovadoras que implementen principios generales de acción". ${ }^{16}$

El uso creciente de los MCC por parte de la policía de proximidad en Ecuador ayuda a recuperar, por tanto, los principios de profesionalización especializada en el análisis del delito sobre pequeños y microterritorios, que son particularmente exigidos por su plataforma informática, base de las estrategias policiales a nivel nacional y fuente fundamental del análisis territorial del delito. ${ }^{17}$

\subsection{Los niveles administrativos de planificación y su relación con los sub-circuitos policiales}

Los niveles administrativos de planificación de Senplades tiene por objeto la coordinación estratégica de los servicios públicos, incluyendo la seguridad ciudadana, y su relación con otras que incidan significativamente sobre el territorio ecuatoriano. Se prevé que estos niveles recojan las "necesidades de la ciudadanía a través de cada uno de sus circuitos, reconociendo en el territorio lo que cada uno necesita". ${ }^{18}$ Uno de los 6 ministerios encargados de la prestación de servicios con este sistema es el Ministerio del Interior y su agencia, la Policía Nacional del Ecuador.

Dado que los pequeños territorios son barrios, zonas concretas, de visibilidad comunitaria y los micro-territorios son esquinas, el fondo de una plaza, u otros sitios donde sea posible la identificación de un hotspot, base del análisis delictivo, los MCC, por su naturaleza, se benefician de los niveles administrativos de planificación de Senplades, puesto que éstos visibilizan y clasifican el territorio hasta el nivel "pequeño", esto es, el distrito y el circuito. Éste último es "la unidad más pequeña donde se prestan servicios públicos. Corresponde a una parroquia o conjunto de parroquias". ${ }^{19}$ Con ello se dirigió la acción pública sobre estos pequeños territorios $y$, en lo referente a la seguridad ciudadana, fue, entonces, la herramienta de planificación pública de mayor importancia para el diseño del nivel de los sub-circuitos policiales por parte del Nuevo Modelo de Gestión Policial.

El sub-circuito policial, por su parte, corresponde a un sector administrativo geográfico fijo y mínimo, aun menor que el circuito, que, a partir de sus características sociales, demográficas y geográficas, reciben distintos tipos de servicios policiales:

"cuentan con la vigilancia comunitaria, atención a las víctimas, educación ciudadana, control de delitos y contravenciones; y recepción de denuncias;

\footnotetext{
${ }^{16}$ FERRET (2004), p. 186

17 WEISBURD (2015), pp. 133-157; SHERMAN (2012), passim.

${ }^{18}$ SECRETARÍA NACIONAL DE PLANIFICACIÓN Y DESARROLLO (2018), passim.

${ }^{19}$ SECRETARÍA NACIONAL DE PLANIFICACIÓN Y DESARROLLO (2012), passim.
} 
bajo principios de integralidad, corresponsabilidad y trabajo con calidad. Teniendo en cuenta las características demográficas y físicas del área urbana de cada población, ciudad o distrito metropolitano se deben organizar y delimitar las UPC". ${ }^{20}$

Un sub-circuito policial es una unidad territorial cercana, en donde se consolidan las estrategias operativas de servicio, auxilio y respuesta a la ciudadanía y se establece mediante el cálculo sobre la base de la distancia lineal recorrida por una patrulla, cuya velocidad promedio es 13,67 km/h, en un turno de trabajo, esto es 8 horas. De modo que, en velocidad por tiempo, ellos cubren $82 \mathrm{~km}$ lineales. ${ }^{21} \mathrm{El}$ sub-circuito facilita que los resultados obtenidos por los MCC puedan traducirse a políticas criminales en el contexto territorial mismo en el que la información fue escogida, con actores y agentes del mismo territorio.

El circuito policial, en cambio, acumula un grupo de circuitos, y es la unidad administrativa más pequeña de la administración gubernamental en general, por debajo de distritos, cantones, sub-zonas y zonas. ${ }^{22}$

\subsection{El uso de los mapas cognitivos compuestos en la política criminal del Ecuador (antecedentes del instrumento)}

Los MCC fueron utilizados por primera vez en el Estado ecuatoriano por el Sistema David del DAID (Departamento de Análisis e Información del Delito, adscrita a la Policía Nacional del Ecuador). Los territorios sometidos a estudio fueron seleccionados de acuerdo con el mayor nivel de conflicto en 2015 y el primer trimestre de 2016 en lo que se refiere a las micro-tráfico y homicidios / asesinatos y, en segundo lugar, robos en todas sus modalidades, cruzados por la UPC, esto es correspondiente a sus sub-circuitos (desde 1 a $2 \mathrm{~km} 2$ ) dentro de las ciudades de Quito, Guayaquil, así como dos cantones fronterizos de la provincia de Esmeraldas. $^{23}$

Los MCC se introdujeron como parte de un cóctel más grande de políticas las cuales incluyeron la profesionalización de la policía, las estrategias de proximidad, la reforma de las bases cartográficas y la generación de una estrategia de análisis delictivo mediante puntos georreferenciados. Este conjunto de políticas, dentro de las que se cuentan los MCC, se asocian con una disminución en los indicadores de criminalidad en los últimos 4 años. ${ }^{24}$

La aplicación del instrumento se deriva de un análisis de aproximadamente 3.000 instrumentos aplicados en el contexto de 20 territorios de alto conflicto en Ecuador para establecer la dinámica espacial de la delincuencia. El estudio se llevó a cabo entre abril y noviembre de $2015 .{ }^{25}$

${ }^{20}$ MINISTERIO DEL INTERIOR (2013), pp. 135

${ }^{21}$ CASTRO-ANIYAR et al. (2015), passim.

${ }^{22}$ SECRETARÍA NACIONAL DE PLANIFICACIÓN Y DESARROLLO (2012), p. 17.

${ }^{23}$ CASTRO-ANIYAR (2015), passim.

${ }^{24}$ CASTRO-ANIYAR et al. (2015), passim. CASTRO-ANIYAR (2018), passim.

${ }^{25}$ CASTRO-ANIYAR (2015), passim. 
Los resultados adquiridos en la aplicación de este instrumento en los lugares antes indicados fueron de gran relevancia, ya que proyectaron información ocultada por diversas razones en las bases informáticas de la Policía Nacional y que permitió el descubrimiento de las dinámicas espaciales de microtráfico, bandas del crimen organizado, enfoques psicosociales, olas de migración, robos, tráficos de drogas, entre otros.

La información recolectada por los MCC respecto al microtráfico permitió poner en relieve la relación entre consumo de sustancias ilícitas y delito, permitiendo al Ministerio del Interior proponer una nueva tabla de tolerancia para el consumo de drogas. Esto muestra la diversidad de las capacidades diagnósticas de la herramienta. ${ }^{26}$

\section{Objetivos y estrategias de la investigación}

El objetivo de la investigación es demostrar la pertinencia que tienen los mapas cognitivos compuestos como instrumento criminométrico a partir de su aplicación en el sub-circuito policial "Murciélago 1", sector Playa Murciélago, de la ciudad de Manta. Para ello, se aplicaron las políticas criminales resultantes del instrumento y se compararon las estadísticas delictivas antes y después, mediante la vía tradicional de denuncias administrativas.

Para poder ilustrar mejor la información que va a vaciarse a continuación, es necesario explicar brevemente cómo funcionan técnicamente los MCC.

1) Se pide al usuario de un espacio definido por la investigación (pero delimitado por las categorías emanadas de los mismos MCC en las aproximaciones piloto) el dibujo de un mapa geográfico del sitio. Se procura recoger información entre víctimas y testigos de delitos.

2) Sobre este proceso se inducen preguntas abiertas sobre puntos de acceso, puntos de tiempo (timespots), categorías delictivas, dinámicas criminales, percepciones y tipos similares de información mediante técnicas de conversatorio etnográfico con patrón temático semiabierto.

3) Sobre la representación gráfica de un espacio construido por la víctima, testigo o perceptor y, siempre en relación al concepto convencional "mapa" o "croquis" (para lograr homogeneidad contrastable de la data), se pide que se marque con colores los lugares que le parecen peligrosos (rojo), hostiles (verde), seguros (azul) y los límites o bordes (amarillo) de ese territorio.

4) Los datos obtenidos por este mecanismo son analizados de una manera etnográfica, mediante la grounded theory lo cual supone que las categorías de análisis no se producen antes de la investigación sino a posteriori, producto de una saturación de la información convenida entre los investigadores en virtud de la homogeneidad o heterogeneidad prenocional de las variables en el campo. ${ }^{27}$

${ }^{26}$ CASTRO (2019a), passim.

${ }^{27}$ KONECKI (2011), pp. 137-140. 
a) Dado que estos mapas se centran en las víctimas y los testigos, por lo que los MCC pueden ser identificados como una herramienta de victimización. ${ }^{28}$

A continuación, se muestra un dibujo realizado por una víctima.

Figura 1. Mapa cognitivo compuesto en el Sub-circuito "Playa Murciélago" de la ciudad de Manta

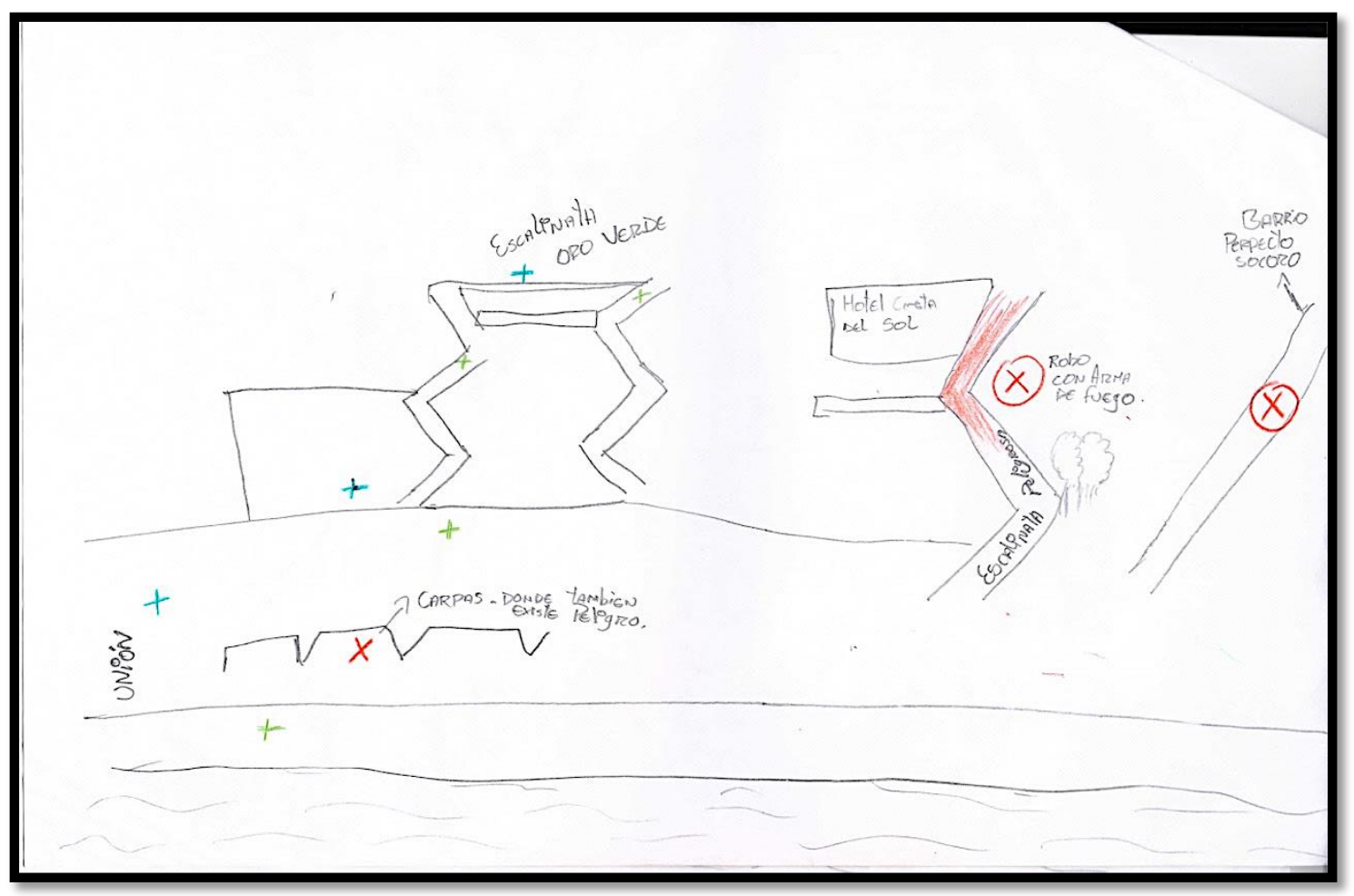

En los MCC podemos observar cómo el informante hace uso de los colores para indicar los lugares que considera peligrosos, hostiles y seguros, identificando así su contribución a la comprensión de la dinámica espacial y los patrones delictivos.

Robert Kitchin ha mostrado la integración del conductismo, la psicología cognitiva y la geografía humana en el concepto mismo de mapeo cognitivo con el fin de validar la importancia de la cognición en las transacciones sociales. A los efectos de este artículo, el autor explica que el mapa $\operatorname{cognitivo}^{29}$ constituye un código dual. Esto implica que la construcción de un mapa facilita la expresión de una dimensión no-analógica sobre una

GUNTER \& DIETRICH (2016), passim.

${ }^{28}$ CASTRO-ANIYAR et al (2017), p. 3.

${ }^{29}$ KITCHIN (1996), passim. Es importante indicar que al hablar Kitchin de mapa o mapeo cognitivo, se refiere al uso que iniciaron Tolman y Lynch, la misma acepción que se utiliza en este artículo y que poco tiene que ver con el mapa conceptual o de ideas, al que recientemente se ha llamado también "mapa cognitivo". 
realidad espacial percibida, en contraste con una realidad verbalizada, que es, por su naturaleza, reconstruida, abstraída y analógica.

Sin embargo, la narración analógica es el tipo de material que recogen las grandes encuestas, como la tradicional encuesta de victimización y las denuncias administrativas, sean policiales, telemáticas o de la Fiscalía. En otras palabras, las fórmulas verbalizadas no expresan directamente una imagen conservada que tiene originalmente una imagen cultural, basándose en la idea de que la cultura, como la identidad, existen no-analógicamente ${ }^{30}$ Esta idea sugiere que, si las imágenes son la forma en que las personas entienden su experiencia de victimización en el espacio (hotspots, microterritorios percibidos peligrosos u hostiles, por ejemplo), es natural suponer que las imágenes relacionadas con los mensajes deben integrarse a la criminometría sea como información directa, o sea como disparador mnemotécnico de una experiencia normalmente compleja y delicada, como lo es la victimización.

El lenguaje gráfico relaja la relación con el instrumentista y no está codificado previamente por los contaminantes mencionados en las fórmulas verbales, mejorando la relación mnémica con la victimización. ${ }^{31}$ La información gráfica, que es naturalmente interesante para las geometrías de la delincuencia, la navegación o enfoques orientados a la defensibilidad ${ }^{32}$ es un pre-contexto óptimo para hacer preguntas como “¿por qué se dibuja esto (en el caso, por ejemplo, de haber un fuerte sesgo entre la dibujo y el mapa geográfico original)?”, ¿Por qué empezó aquí?’' ¿Por qué se utiliza tanto (o tan poco de color rojo) en este momento?’, ‘¿Qué es lo que quiere decir con hostilidad (o peligro) en este lugar?” O “¿Por qué ocurrió precisamente aquí?”. Detrás de estas preguntas subyace la pregunta central: “¿Cuáles son los patrones espaciales de la delincuencia en este territorio y en que situaciones se les asocian?"33

Como técnica, el instrumentista lleva un diario de campo en el que escribirá la descripción y la categorización de los datos recolectados por medio del instrumento. Al hablar de descripción, nos referimos a explicar la manera en cómo el informante empieza a dibujar el mapa, por ejemplo, si lo hace de modo secuencial o si lo hace desde su perspectiva visual, o de manera coordinada (imaginando eficientemente las proporciones totales del territorio desde el cielo), percatándonos de cómo explica el dibujo y, en caso de que sea víctima o testigo, la forma en que narra la reconstrucción de los hechos del delito. En cuanto a la categorización, se plasman sobre una matriz los puntos específicos del hecho, a través de categorías que suelen ser coincidentes como: el tiempo, el espacio, dinámica, modalidad, alteridad, hostilidad, disparadores delictivos y seguridad jurídica. Éstas sirven de base para aportar a comprender la situación delictual y, en un plano más grande, comparando patrones inter-territorialmente, las dinámicas espaciales del delito.

\footnotetext{
${ }^{30}$ KITCHIN (1996), pp. 56-84

${ }^{31}$ LOOR et al. (2019), passim.

${ }^{32}$ NEWMAN (1996), passim.

${ }^{33}$ PAULSEN et al. (2012) p. 23.
} 

análisis de la situación delictual a partir de un pequeño territorio"

\section{Relevancia de Manta y Playa Murciélago como laboratorio de análisis del delito}

Manta es uno de los territorios relativamente más conflictivos dentro del Ecuador ${ }^{34}$. Según las denuncias administrativas recolectadas por la Policía Nacional y el Sistema David (DAID), se revela que la Playa Murciélago es uno de los territorios más conflictivos y con mayor victimización dentro del cantón Manta ${ }^{35}$. Ello determinó la delimitación de esta investigación para poder prevenir el delito en este pequeño territorio.

Playa Murciélago en un sitio recreacional en el centro de la ciudad de Manta, rodeado de importantes vías de acceso, con restaurantes, al lado del Mall más importante de la Zona 4, $\mathrm{y}$ varios otros servicios recreativos. Es un punto de afluencia central del turismo local y nacional, con afectación del turismo internacional en todas las épocas del año. Este contexto genera que la afluencia de población flotante es mucho mayor que en todo el cantón, con los riesgos de oportunidad delictiva que esto puede generar.

Algunos visitantes de la playa buscan puntos alejados donde se puedan relajar, generalmente muy poco concurridos, a veces no vigilados, aislados geográficamente y con poca iluminación, generando una oportunidad delictiva para que el victimario efectúe con mayor facilidad su objetivo. Estos descubrimientos coinciden con "la teoría del patrón delictivo" que señala los elementos que convergen para crear un hecho delictual, aunque con más énfasis en cómo los infractores seleccionan y buscan blancos adecuados. Apoyada en la elección racional (rational choice), las actividades cotidianas, y la criminología ambiental, la teoría del patrón delictivo se centra en la convergencia en tiempo y espacio de la motivación de los infractores y las características del blanco de la acción delictiva en toda la estructura de una oportunidad. ${ }^{36}$

\section{Estudio de hotspots y microterritorios de Playa Murciélago a través de los MCC: factores generales de la situación delictiva.}

La incursión en campo se realizó durante varios días del mes de diciembre del 2017 , aplicándose $20 \mathrm{MCC}$ desde diferentes ángulos triangulados. Luego se compararon los resultados con días similares de la semana (concretamente, los viernes) en diferentes fechas de enero y mayo del 2018. La intención de estas tres muestras fue comparar los cambios del cambio de comandante de la UPC. El total de personas instrumentadas fueron 85, correspondientes a $85 \mathrm{MCC}$.

\footnotetext{
34 BARCIA et al. (2018), passim.

${ }^{35}$ MINISTERIO DEL INTERIOR (2018), passim.

${ }^{36}$ BRANTINGHAM y BRANTINGHAM (1993), pp. 261-264
} 
Figura 2. Visión satelital de Playa Murciélago

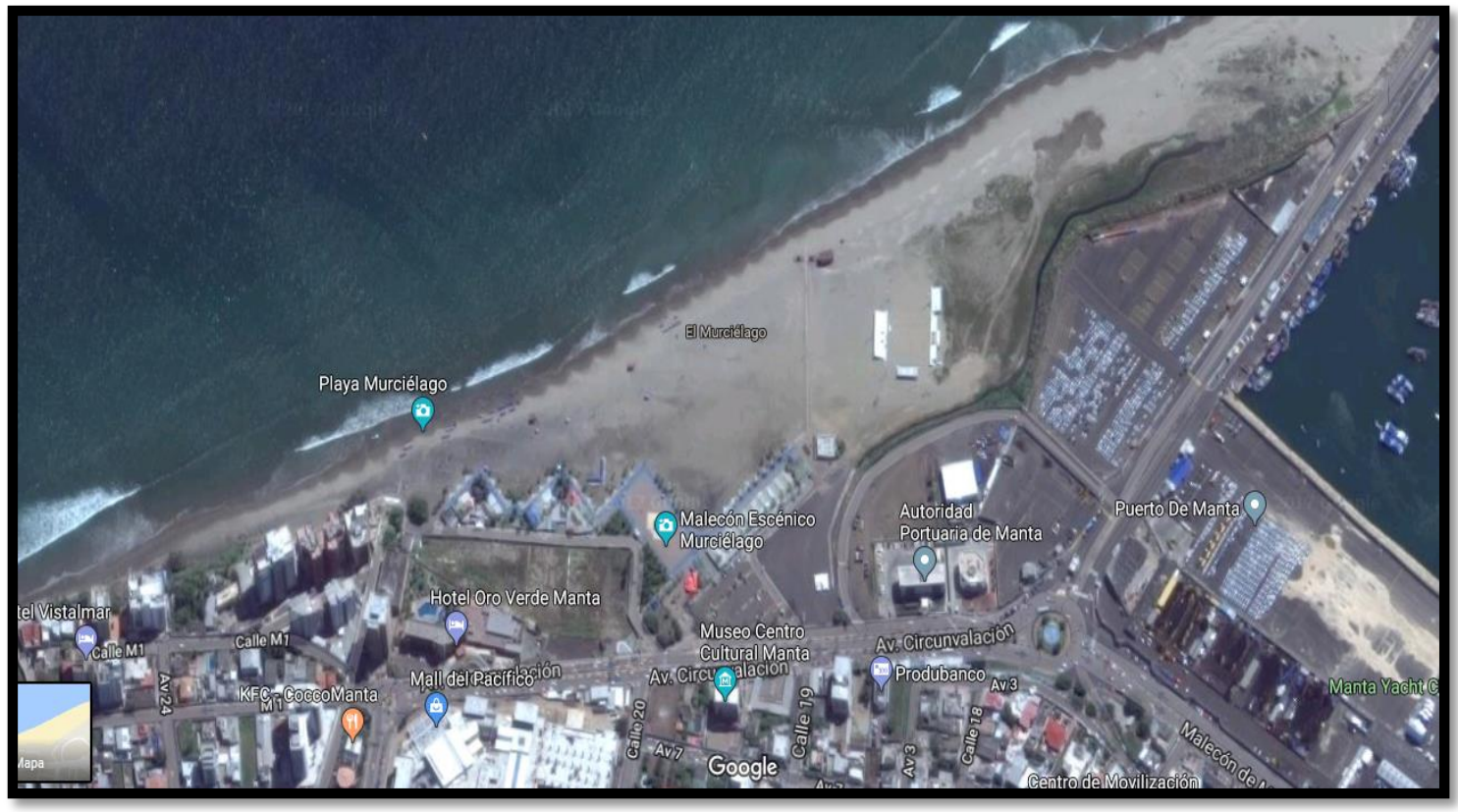

A pesar de que hubo muchos sitios donde las personas fueron victimizadas, es muy notable que solamente saturaron algunos pocos sitios y que uno de ellos está alrededor de unos 10 metros de la UPC (Unidad de Policía Comunitaria con servicio de proximidad a la playa y a lo largo de un segmento costero). Siendo éste el sitio denominado en la investigación (a partir de los informantes) las Palmeras, que se refiere al conjunto de palmeras que están a la salida e izquierda de las "escalinatas que bajan del hotel Oro Verde" (ver figura 5).

En ese punto sobresalen definiciones similares del lugar, relacionadas con oportunidad delictiva por poca defensibilidad (aislamiento de ángulos visuales protectores y poca iluminación), venta, consumo de marihuana, agresión con escopolamina, armas de fuego y armas blancas. Dada su cercanía, es posible asociar este hotspot al siguiente punto que son las "escalinatas del Mirador" que se refiere a las escalinatas que bajan del "Hotel Oro Verde", las cuales se perciben aisladas y poco visibles del público, por tanto, con mayor nivel de indefensibilidad (ver figura 5). Aquí encontramos actividades delictivas como robo con cómplices motorizados.

En el estudio también encontramos actividad delictiva en las escalinatas "Hostal de Sol" (ver figura 5). Éste se encuentra saliendo del estacionamiento del Hostal y desemboca en la costa, y también, la parte costera frente a la salida de la escalinata. A pesar de que la costa misma no satura, se le integra a las descripciones recibidas de la dinámica general, dada la cercanía a las escalinatas del mirador y palmeras.

Aunque víctimas, testigos e informantes diferencian los tres hotspots porque sus experiencias son diferentes, objetivamente es posible ver que hay un comportamiento delictivo similar en un territorio cuyos hotspots están cerca. Esto en parte se aprovecha por los problemas de los ángulos de visibilidad: el hecho de los tres puntos (tal como puede observarse en el mapa de la figura 5) corresponden a un borde cóncavo que hace difícil la visibilidad en el ángulo 
horizontal a la playa.Este punto cuenta además con la oportunidad delictiva de contar con una escalinata que conecta la playa con el barrio Perpetuo Socorro. En general, las escalinatas consisten en oportunidades delictivas para personas que ingresan a la playa, depredan y escapan por el barrio.

A lo largo del borde noreste de la Playa Murciélago, específicamente al noreste del estadio, encontramos una barrera de rocas denominada "Zona rocosa 1" (ver figura 5). Este hotspot se asoció a la percepción y victimización de violación, acoso sexual, escopolamina y hurto a pie durante el periodo de oscuridad. La debilidad de este punto, aparte de su lejanía y asilamiento, consiste en que también es asistido por parejas que buscan intimidad, lo que les hace vulnerables a agresores, creando una oportunidad delictiva. Existe una Zona rocosa 2 como otro punto saturado e integrable a la dinámica delictiva en general de esta parte de la playa. Las rocas están colocadas artificialmente con palmeras frente a una loma pequeña, un poco más al Sur de las escalinatas del "Iron Man" (ver figura 5). Este punto, junto a "Escalinatas del Hostal de Sol" y "Escalinatas del Mirador", se aprovechan de los pasos de escape entre la playa y el barrio Perpetuo Socorro, que permiten depredar y huir.

\subsection{Fases de la aplicación del instrumento}

Antes de describir las dinámicas espaciales del delito, es importante apuntar que la aplicación de los MCC en todo el territorio del sub-circuito policial, concretamente, en Playa Murciélago, se dividió en dos fases (llamados before y after, por el anglicismo usual en políticas públicas).

En la primera etapa (before), la población instrumentada muestra un profundo sentimiento de inseguridad asociable al espacio y a la seguridad jurídica-ciudadana percibida. Solo dos personas indicaron sitios seguros cerca de la UPC, evidenciando que la gente recurre a la autoprotección, no como una medida adicional, sino por la percepción de que la policía y otras agencias de seguridad no hacen su trabajo apropiadamente.

Las dinámicas delictivas son heterogéneas tanto en el before como en el after, lo que implica un número de emprendimientos delictivos, hotspots, puntos de victimización y tipos de víctimas diferentes y variados, no fácilmente susceptibles de categorizar establemente.

Tanto en el before como en el after, los pasos alternativos desde la ciudad a la playa (escalinatas del: "ironman", "Hostal del sol", "Mirador", y algunos otros pasos pequeños, rústicos, más allá de la última zona rocosa del Suroeste) permiten la depredación directa y vulneran los espacios. La entrada principal es normalmente percibida como segura o sin incidentes.

Los espacios alejados, pocos iluminados, correspondientes a los extremos percibidos del territorio, son usualmente utilizados para búsqueda de intimidad, consumo de alcohol, sustancias ilícitas, o para contactos románticos y/o sexuales, generando así la vulnerabilidad ante la oportunidad delictiva. Esto corresponde a la dinámica de los "extremos" del territorio, de más difícil visibilidad, baja defensibilidad, y por tanto más adecuables a los contactos íntimos y la oportunidad delictiva. 
Los hostpots no saturados son muchos, mostrando el carácter flotante de los usuarios como de los emprendedores delictivos. Esto debilita la formación de dinámicas delictivas estables en el tiempo y es una fortaleza situacional favorable a la acción policial. Es crucial tener conciencia de esta fortaleza antes de que se estabilicen las dinámicas delictivas y su control sea más complejo.

En la segunda etapa (after) como resultado de que se implementaron estrategias policiales basadas en un diagnóstico similar al que se presenta actualmente, se produce un incremento de la percepción de seguridad sobre los hotspots que constituyen los pasos de depredación y huida. Sin embargo, desaparecen del ángulo de la acción policial otros hotspots, complementando la visión de heterogeneidad y condición flotante, tanto de victimarios como víctimas.

Estos nuevos hotspots aun invisibles (ver figura 3), son los que muestran fallas de defensibilidad urbana y de visibilidad en las zonas extremas del territorio. Sin embargo, allí se producen delitos de robo, hurto y en contra de la integridad sexual de los usuarios, saturándose claramente estas prácticas. Víctimas y testigos de delitos de tipo sexual declaran no haber denunciado y exponen que sus razones son:

1) Ausencia de confianza en la eficiencia de la policía.

2) Vergüenza (no querer exponer la intimidad del suceso).

3) Un caso en que la denuncia efectivamente fue hecha, pero fue desestimada por el agente de seguridad dando a entender que el sujeto buscaba "algo así" por razón de la hora en que se cometió ( 9 pm).

Estos hechos se produjeron tanto antes como después del cambio de estrategia de la UPC. Por otro lado, los policías ignoraron los acosos sexuales contra corredoras deportivas en las zonas del estacionamiento de la entrada, así como contra las muchachas y otras parejas jóvenes que buscan intimidad en las zonas rocosas.

También se indicó desconocimiento de un caso de tentativa de acoso pedofílico, del cual referencia el MCC de una misma policía de la UPC. Otro caso de la violación homosexual también se desconoció, frente a la zona cóncava, aunque corresponde al período anterior al cambio de estrategias.

Con mucha mayor profundidad, los MCC esta vez detectaron el sistema de oportunidades delictivas que suceden entre las tres escalinatas y el corredor de tierra al suroeste de las zonas rocosas. También se detectó el uso de motocicletas como apoyo al robo, una práctica particularmente usual en toda la ciudad de Manta y Portoviejo. Esto llevó a considerar que quizás se trataba de una red delincuencial contando con alianzas más allá de la calle, detectando así actores delictivos dentro del barrio perpetuo socorro, en la calle M1, precisamente, la que conecta por la parte de arriba las tres escalinatas y, en especial las de "costa del sol" con la del "ironman" (ver figura 5). 
CASTRO, Daniel; PIHUAVE, Pedro; PARRALES, Rosa; RAMÍREZ, Leticia; KARLO, Jean: "El mapa de las víctimas. Pertinencia de los mapas cognitivos compuestos en el análisis de la situación delictual a partir de un pequeño territorio"

\section{Relato policial}

Figura 3. MCC del comandante de la policía en el territorio

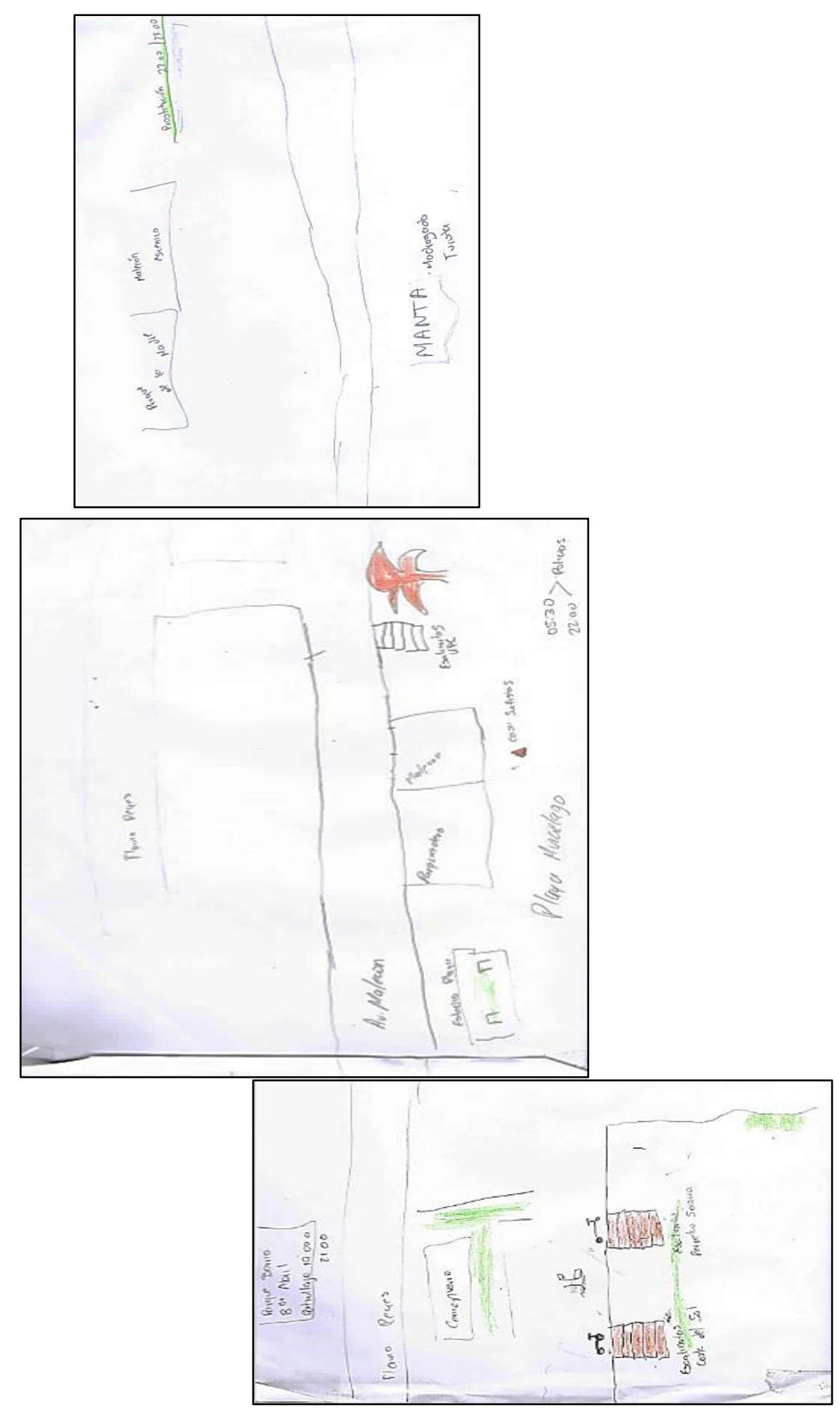


En la UPC de la Playa el Murciélago, se instrumentó un MCC al sub-teniente Sosa, a cargo del sub-circuito, y responsable de las últimas estrategias sobre la playa. Pudimos observar que empezó a realizar el mapa desde la Av. Malecón justo por las "letras de MANTA" (indicador de la ciudad al borde del malecón), mostrando la visión integrada de otros territorios del sub-circuito con la playa. Fue un mapa bien estructurado, coordinado y secuencial en donde marcó como sitios peligrosos las escalinatas del ironman (ver figura 5), las escalinatas del hotel "Costa del Sol" y "las palmeras" al lado de las escalinatas de la UPC. Esto quiere decir que el subteniente confirma los sitios peligrosos que ya nos han saturado en los instrumentos aplicados anteriormente.

La primera evidencia de las ventajas diagnósticas de los $\mathrm{MCC}$, es que en el mapa del comandante bloquea o disminuye la peligrosidad del territorio que se extiende desde la "casa de los surfistas" hasta la "zona rocosa" del noreste, contradiciendo a lo revelado por parte de los informantes a quienes se le aplicaron los MCC. Precisamente, son estos puntos donde específicamente se producen, además de los delitos de robo y hurto, aquellos en contra de la integridad sexual de los usuarios.

En la conversación, el subteniente nos expresó que se incluyó un set de estrategias que resultaron nuevas y que tuvieron relativo impacto positivo en la reducción del delito para el territorio. La más detallada de ellas consistió en ubicar una pareja de personal policial de manera permanente en los hotspots identificados por la UPC y, en otros momentos, implememntar un sistema de patrullaje a pie en la que se detienen en cada hotspots identificado por la UPC durante 10 minutos, antes de continuar la ronda. Esta estrategia parece haber sido la fuente del mejoramiento de la percepción de seguridad entre el before y el after. Aunque, dado que la estrategia establece previamente los hotspots conflictivos, con base en los reportes de la comandancia anterior, probablemente esto influyó en la invisibilidad de los hotspots detectados por los MCC.

Otra estrategia consistió en comenzar el patrullaje a las 4 AM, para incluir la protección a los corredores deportivos. No se obtuvieron resultados acerca de la eficiencia de ésta.

Por tanto, los MCC permitieron, en relación al testimonio del comandante a cargo:

1) Visibilizar los delitos de acoso sexual

2) Visibilizar los delitos de violación

3) Confirmar que estrategias adecuadas en los hotspots donde los MCC y la policía coinciden, generan una clara estimación de reducción del delito

4) Visibilizar redes delincuenciales que se inician más allá del subcircuito, hacen alianzas con depredadores de un barrio vecino y aprovechan oportunidades de defensibilidad urbana y venta de drogas, cuyos puntos fueron detectados, en la periferia de la playa.

5) Confirmar el uso de los pasos a los barrios, como una oportunidad de escape y ocultamiento de los depredadores, tal como había percibido la policía.

6) La presencia de capas de protección comunitaria a los depredadores en los barrios vecinos, cuya especificidad y puntualidad fue finalmente visibilizada gracias a los MCC. 


\subsection{Resultados en víctimas, testigos y percepciones}

Los resultados obtenidos por medio de los MCC fueron relativamente más eficaces criminométricamente en cuanto a las situaciones y dinámicas espaciales relevadas, que los mapas térmicos de denuncias disponibles por la policía ${ }^{37}$ como por el testimonio empírico de la comandancia de la UPC correspondiente

Los MCC nos revelaron muchos datos importantes con respecto a los patrones delictivos en las escalinatas hotel "Costa del Sol", escalinatas del "ironman", "las palmeras" entre "el mirador" y "oro verde", "zona rocosa noreste", "zona rocosa suroeste", "zona cóncava" y "el estadio". En cuanto a defensibilidad, la cual se refiere a la oportunidad que tiene el emprendedor delictual otorgada por las condiciones de visibilidad y autoprotección infraestructural urbanística (poca iluminación, lugares solitarios, callejones estrechos, etc.) y los disparadores, factores no relacionados pero si asociados a favorecer la comisión de un crimen (drogas, alcohol, marihuana) se observaron constantes: relativa invisibilidad territorial, bajas condiciones de autoprotección, psicoactivos en victimarios y víctimas y actividad sexual relativamente expuesta. De manera inconstante, no saturada, encontramos la alteridad entre la víctima y el victimario.

El uso de vehículos, armas y otros recursos, así como los timespots que reflejan la hora en la que este micro-territorio se torna más peligroso. Todo ello indica un territorio relativamente sencillo para el diseño de políticas criminales situacionales. En total, los delitos concurridos en este pequeño territorio fueron: robo con amenaza y a veces con arma blanca o contundente, venta y consumo de marihuana, agresión con escopolamina, armas de fuego, armas blancas, hurto, acoso sexual, violaciones homosexuales y acoso pedofílico.

Los resultados encontrados en los mapas cognitivos compuestos en el subcircuito de la playa el murciélago de la ciudad de Manta fueron los siguientes:

Figura 4. Algunas categorías consolidadas de la matriz de análisis

\begin{tabular}{|c|c|c|c|c|c|c|c|}
\hline Hotspots & $\begin{array}{c}\text { Escalina } \\
\text { ta } \text { hostal } \\
\text { costa del } \\
\text { sol }\end{array}$ & $\begin{array}{c}\text { Palmeras } \\
\text { entre el } \\
\text { Escalina } \\
\text { ta } \\
\text { IronMan } \\
\text { oro verde } \\
\text { y zona } \\
\text { rocosa } \\
\text { noreste }\end{array}$ & $\begin{array}{c}\text { Zona } \\
\text { rocosa } \\
\text { noreste }\end{array}$ & $\begin{array}{c}\text { Zona } \\
\text { rocosa } \\
\text { suroest } \\
\text { e }\end{array}$ & $\begin{array}{c}\text { Zona } \\
\text { cóncava }\end{array}$ & Estadio \\
\hline $\begin{array}{c}\text { Descripc } \\
\text { ión }\end{array}$ & & & $\begin{array}{c}\text { (entre } \\
\text { mirador } \\
\text { Oro Verde } \\
\text { y Zona }\end{array}$ & $\begin{array}{c}\text { Ubicaba } \\
\text { entre } \\
\text { Autorida } \\
\mathrm{d}\end{array}$ & $\begin{array}{c}\text { Se } \\
\text { refiere } \\
\text { a los } \\
\text { rompeo } \\
\text { lon que }\end{array}$ & $\begin{array}{c}\text { Comprend } \\
\text { e los } \\
\text { lugares } \\
\text { antes } \\
\text { señalados, }\end{array}$ & \\
\hline
\end{tabular}

${ }^{37}$ DAID 2016, passim. 
Polít. Crim. Vol. 15, № 30 (Diciembre 2020), Art. 11, pp. 840-

[http://politcrim.com/wp-content/uploads/2020/12/Vol15N30A11.pdf]

\begin{tabular}{|c|c|c|c|c|c|c|c|}
\hline & & & $\begin{array}{c}\text { Rocosa } \\
\text { Noreste) }\end{array}$ & $\begin{array}{c}\text { y el } \\
\text { Estadio }\end{array}$ & $\begin{array}{c}\text { están } \\
\text { ubicado } \\
\text { s bajo } \\
\text { los } \\
\text { conjunt } \\
\text { o } \\
\text { habitaci } \\
\text { onales } \\
\text { del } \\
\text { sector } \\
\text { suroest } \\
\text { e de la } \\
\text { playa, } \\
\text { se } \\
\text { encuent } \\
\text { ran a } \\
\text { aproxi } \\
\text { madam } \\
\text { ente } 10 \\
\text { metros } \\
\text { de la } \\
\text { escalina } \\
\text { ta del } \\
\text { ironma } \\
n\end{array}$ & $\begin{array}{c}\text { empezand } \\
\text { o desde las } \\
\text { palmeras } \\
\text { ubicadas } \\
\text { junto al } \\
\text { Mirador } \\
\text { del Oro } \\
\text { Verde, } \\
\text { extendiénd } \\
\text { ose hasta } \\
\text { la } \\
\text { Escalinata } \\
\text { del Iron } \\
\text { Man }\end{array}$ & \\
\hline $\begin{array}{l}\text { Time } \\
\text { spots }\end{array}$ & $\begin{array}{l}\text { Hora de } \\
\text { almuerzo } \\
\text { /5pm }\end{array}$ & $\begin{array}{l}\text { Todos } \\
\text { los dias }\end{array}$ & $8 \mathrm{pm}$ & $\begin{array}{l}\text { todos los } \\
\text { días } 8 \mathrm{pm}\end{array}$ & & $\begin{array}{l}\text { todos los } \\
\text { días / 5pm } \\
\text { / 8pm }\end{array}$ & $\begin{array}{l}\text { todos } \\
\text { los días } \\
\text { / en la } \\
\text { mañana }\end{array}$ \\
\hline $\begin{array}{c}\text { Ventana } \\
\text { rota/ } \\
\text { defensib } \\
\text { ilidad }\end{array}$ & $\begin{array}{c}\text { Contami } \\
\text { nación/pi } \\
\text { edras }\end{array}$ & Piedras & & & & & \\
\hline $\begin{array}{c}\text { Dispara } \\
\text { dor }\end{array}$ & Drogas & $\begin{array}{c}\text { Marihua } \\
\text { na }\end{array}$ & $\begin{array}{c}\text { Drogas } \\
\text { Marihuana }\end{array}$ & $\begin{array}{c}\text { poca } \\
\text { ilummin } \\
\text { ación / }\end{array}$ & drogas & $\begin{array}{c}\text { drogas / } \\
\text { marihuana }\end{array}$ & $\begin{array}{c}\text { drogas } \\
\text { x2 }\end{array}$ \\
\hline $\begin{array}{c}\text { Alterida } \\
\text { d } \\
\text { victima }\end{array}$ & Parejas & & $\begin{array}{c}\text { extranjero } \\
\mathrm{s}\end{array}$ & parejas & & & \\
\hline $\begin{array}{l}\text { Alterida } \\
\text { d } \\
\text { victimar } \\
\text { io }\end{array}$ & $\begin{array}{l}\text { Jóvenes/ } \\
\text { jóvenes } \\
\text { de } \\
\text { estatura } \\
\text { pequeña }\end{array}$ & $\begin{array}{c}\text { Jóvenes/ } \\
\text { "fachoso } \\
\text { s"/jóvene } \\
\text { s } 8 \text { de } \\
\text { abril }\end{array}$ & Jóvenes & $\begin{array}{c}\text { viven } \\
\text { "fumone } \\
\text { s" / } \\
\text { hombre } \\
35 \text { años }\end{array}$ & $\begin{array}{c}\text { "fachos } \\
\text { o" }\end{array}$ & jóvenes & jóvenes \\
\hline
\end{tabular}


CASTRO, Daniel; PIHUAVE, Pedro; PARRALES, Rosa; RAMÍREZ, Leticia; KARLO, Jean: "El mapa de las víctimas. Pertinencia de los mapas cognitivos compuestos en el análisis de la situación delictual a partir de un pequeño territorio"

\begin{tabular}{|c|c|c|c|c|c|c|c|}
\hline $\begin{array}{c}\text { Acción } \\
\text { delictiva } \\
\text { / } \\
\text { modalid } \\
\text { ad }\end{array}$ & $\begin{array}{c}\text { arma } \\
\text { blanca } \\
\mathrm{x} 2 / \text { robo } \\
\text { colectivo } \\
/ \\
\text { acecho/r } \\
\text { obo con } \\
\text { cuchillo }\end{array}$ & $\begin{array}{c}\text { Arma } \\
\text { blanca/ar } \\
\text { ma de } \\
\text { fuego/ } \\
\text { robo con } \\
\text { cuchillo. }\end{array}$ & $\begin{array}{c}\text { arma } \\
\text { blanca / } \\
\text { violación( } \\
1-1)+ \\
\text { robo con } \\
\text { cuchillo(1- } \\
1)+ \text { robo } \\
\text { con armas } \\
\text { de fuego + } \\
\text { agresión } \\
\text { con puñal }\end{array}$ & $\begin{array}{c}\text { arma } \\
\text { blanca } \\
\text { x2 / } \\
\text { acoso } \\
\text { sexual x2 } \\
\text { / acecho } \\
\text { / cuchillo } \\
\text { grande / }\end{array}$ & $\begin{array}{c}\text { cuchillo } \\
\text { grande }\end{array}$ & $\begin{array}{c}\text { arma } \\
\text { blanca x4 / } \\
\text { violación( } \\
1-1)+ \\
\text { robo con } \\
\text { cuchillo(1- } \\
1)+ \text { robo } \\
\text { con armas } \\
\text { de fuego + } \\
\text { agresión } \\
\text { con puñal }\end{array}$ & $\begin{array}{l}\text { acoso } \\
\text { sexual }\end{array}$ \\
\hline
\end{tabular}

Figura 5. Distribución de hotspots en el mapa y su leyenda

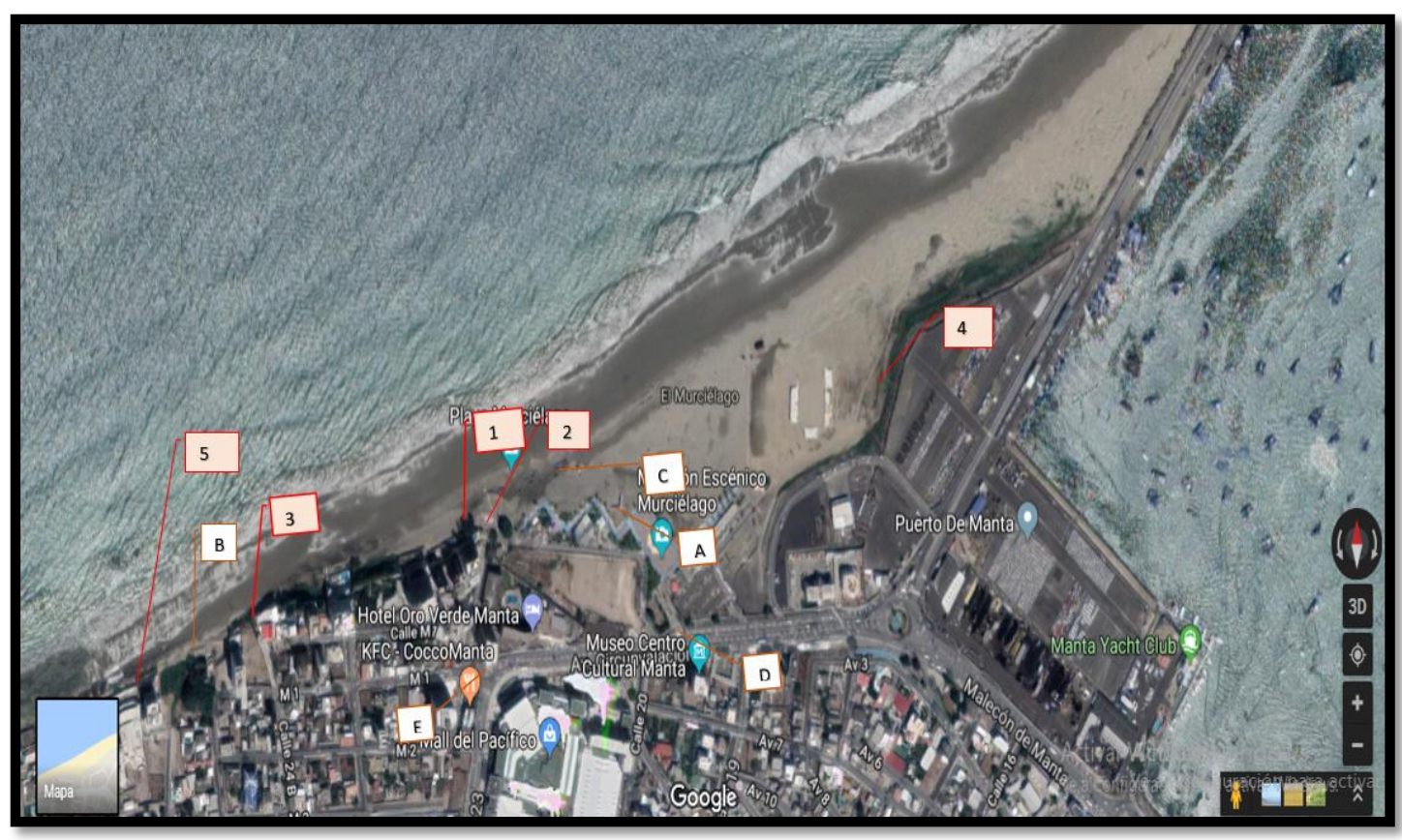

NOTA: En rosado se colocan los hotspots saturados. En café claro se colocan los no saturados pero que tienen una incidencia relativa que, en conjunto pueden revelar dinámicas.

\begin{tabular}{|c|l|}
\hline PUNTO & \multicolumn{1}{|c|}{ LUGAR } \\
\hline $\mathbf{1}$ & $\begin{array}{l}\text { Palmeras } \\
\text { (Ubicadas junto al Mirador que tiene salida al Hotel Oro Verde) }\end{array}$ \\
\hline $\mathbf{2}$ & Escalinatas del Mirador que tiene salida al Hotel Oro Verde \\
\hline $\mathbf{3}$ & Escalinata del Hostal Costa del Sol \\
\hline $\mathbf{4}$ & $\begin{array}{l}\text { Zona Rocosa 1 Noreste } \\
\text { (Al norte del Estadio } \\
\text { o y próxima al Puerto) }\end{array}$ \\
\hline
\end{tabular}




\begin{tabular}{|l|l|}
\hline $\mathbf{5}$ & $\begin{array}{l}\text { Zona Rocosa 2 Suroeste } \\
\text { (Detrás del Conjunto Habitacional Ibiza, más al sur de las escalinatas } \\
\text { del Iron Man) }\end{array}$ \\
\hline $\mathbf{A}$ & $\begin{array}{l}\text { Cabañas (Locales comerciales en los que se realiza la venta de } \\
\text { souvenirs, ubicados frente a los restaurantes de la zona occidental) }\end{array}$ \\
\hline $\mathbf{B}$ & Cuevas (Iron Man) \\
\hline $\mathbf{C}$ & $\begin{array}{l}\text { Carpas (carpas con sillas ubicadas a lo largo de la playa para su } \\
\text { alquiler a los turistas) }\end{array}$ \\
\hline $\mathbf{D}$ & Entrada Principal \\
\hline E & Redondel del Mall del Pacífico \\
\hline
\end{tabular}

\subsection{Dinámica delictiva}

Las dinámicas detectadas con la data obtenida por parte de los informantes, fueron:

1) La presencia de poca gente genera que los emprendedores delictivos encuentren con más facilidad el momento para delinquir, aprovechándose de la soledad del territorio, baja autoprotección y baja visibilidad en el eje horizontal a la playa.

2) Los perceptores se sienten susceptibles a robos cuando se encuentran en presencia de mucha gente (feriados), debió al roce, y a que los agentes policiales no pueden movilizarse de una manera frecuente por el exceso de visitantes. Sin embargo, esta percepción no coincide con una victimización saturada.

3) Otros de los aspectos declarados como dinámica delictiva es que la búsqueda de intimidad para consumir alcohol, sustancias ilícitas, o para tener contactos románticos y/o sexuales, constituye un elemento atrayente de la oportunidad, por el hecho de generar en el depredador la percepción de que la víctima es particularmente vulnerable.

4) Se presentan robo con cómplice en motos en los pasos al barrio (tanto en las escalinatas del "mirador", "escalinatas del hotel Costa del Sol" y "escalinatas del ironman"). Ello permite que los victimarios utilicen rápidamente las rutas de escape luego de haber cometido un hecho delictual. En los mapas que se triangularon sobre los barrios asociados a las dinámicas delictivas, se apreció la incidencia regular de robos con vehículo en contra de víctimas pedestres, mayormente de sexo femenino. Ambas acciones delictivas pueden estar vinculadas. En este sentido, el aumento reciente del patrullaje en el barrio Perpetuo Socorro es percibido por los usuarios del espacio como acertado. Sin embargo, las rutas de escape, consumo de drogas y alianzas incluyen a otro barrio asociado a la actividad delictiva, el "8 de Abril", pero que, al no pertenecer al "Subcircuito Muricélago 1", dificulta su invisibilidad en la dinámica delictiva del relato policial, así como la coordinación de la política de patrullaje.

e.- Refiriéndose a la ruta de escape del "ironman", los delincuentes bajan desde el barrio 8 de abril, usan como escondite el cementerio en la parte superior de la playa, se asocian con los depredadores del Perpetuo Socorro y consumen sustancias ilícitas obtenidas en el mismo, 
aprovechando las paredes derruidas que quedaron del cementerio luego del terremoto del 2016 y el no funcionamiento del "ojo de águila" (cámaras de seguridad públicas instaladas con el sistema de denuncias telemáticas ECU 911) que se encuentra en la esquina del cementerio. La dinámica incluye entonces la participación de, al menos, dos grupos de emprendedores delictivos que hacen base en barrios diferentes y en sub-circuitos policiales diferentes. Las rutas de escape producen circuitos de acción que sobrepasan la actividad del territorio de acción de la policía comunitaria apostada en el territorio, dificultando su visibilidad diagnóstica.

\section{Comparativos}

\subsection{Comparativo instrumental por denuncias y reportes policiales}

Entre los resultados que reflejan el Departamento de Análisis e Información del Delito, adscrito la Policía Nacional del Ecuador a través de su Mapa de Concentración del Delito (MCD) y los MCC sobre el pequeño territorio Playa Murciélago es posible presentar la siguiente comparación:

1) Semejanzas: los hotspots saturados en los MCC son el "Mirador del hotel Costa del Sol" y "las Palmeras" (Ubicadas junto al "Mirador" que tiene salida al "Hotel Oro Verde") catalogados como micro-territorios con alto riesgo de victimización, asimismo, podemos encontrar en el mapa de concentración de delincuencia (MCD) del DAID, determinado por las denuncias administrativas y las llamadas de auxilio ECU911 (Figura 6).

2)Diferencias: dentro del MCD podemos observar que en la calle atrás de los restaurantes cercanos a la UPC y la entrada principal se acentúa un gran número de denuncias, información que no fue reflejada por los MCC. Esto estaría mostrando que el mayor número de denuncias no corresponde al mayor número de victimizaciones, sino a la necesidad del local comercial en formalizar el testimonio de un incidente.

Los MCC revelan que los hotspots altamente saturados "Zona rocosa 1" (noreste del mapa de Murciélago) y "Zona rocosa 2" (suroeste), y el punto entre la "casa de los surfistas" y la primera zona rocosa, han sido ignorados como micro-territorios conflictivos dentro del subcircuito Playa Murciélago por el MCD. Estos puntos dentro de los MCC son especialmente las zonas donde se originan delitos de robo, hurto y contra de la integridad sexual hacia las personas recurrentes a este centro turístico. (Figura 6) 
Figura 6. Mapa térmico de la Policía Nacional, basado en denuncias y reportes (realización propia a partir de Ministerio del Interior, 2018 ${ }^{38}$

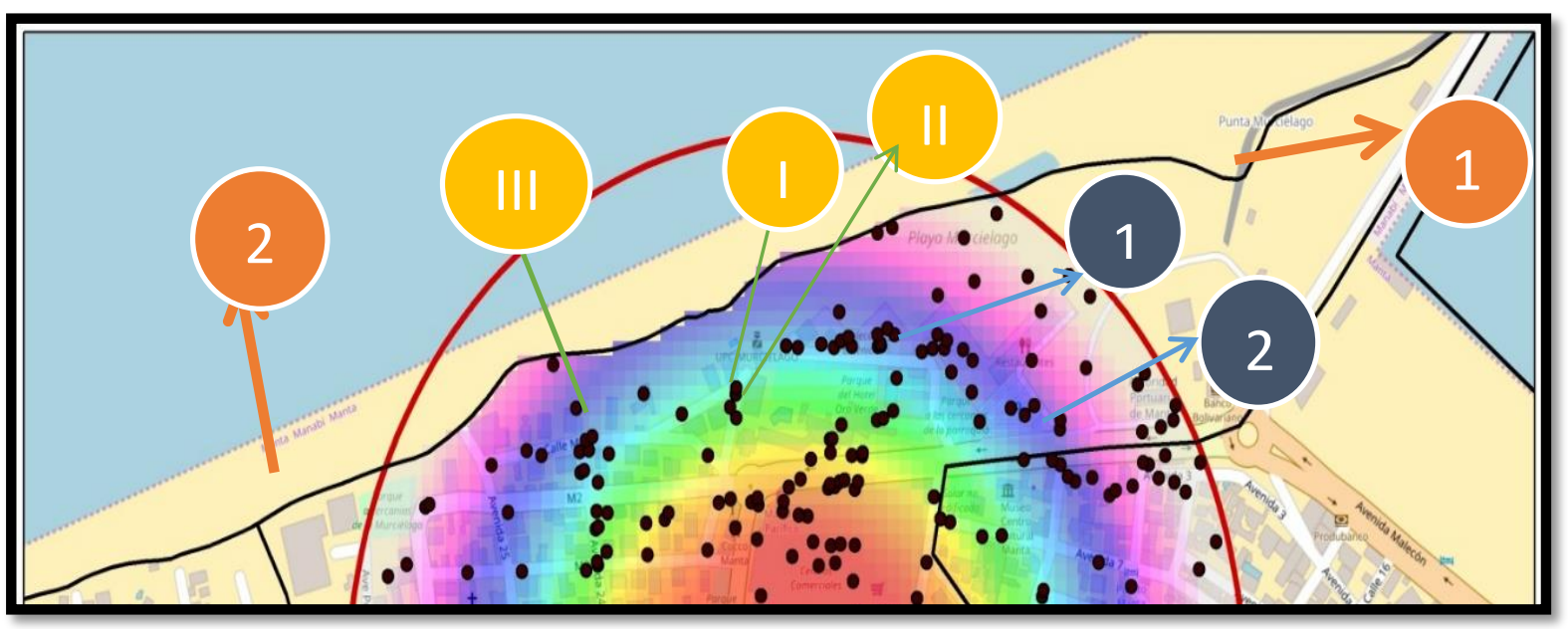

\begin{tabular}{|l|l|}
\hline \multicolumn{2}{|c|}{ LEYENDA } \\
\hline$\underline{\underline{\text { UUNTO }}}$ & $\underline{\underline{\text { CONCIDENCIAS }}}$ \\
\hline I & $\begin{array}{l}\text { Palmeras (Ubicadas junto al Mirador que tiene salida al Hotel } \\
\text { Oro Verde) }\end{array}$ \\
\hline II & Escalinatas del Mirador que tiene salida al Hotel Oro Verde \\
\hline III & Escalinata del Hostal Costa del Sol \\
\hline$\underline{\text { PUNTO }}$ & $\underline{\text { LUGAR MCC }}$ \\
\hline 1 & $\begin{array}{l}\text { Zona Rocosa 1 Noreste (Al norte del Estadio y próxima al } \\
\text { Puerto) }\end{array}$ \\
\hline 2 & $\begin{array}{l}\text { Zona Rocosa 2 Suroeste (Detrás del Conjunto Habitacional } \\
\text { Ibiza, más al sur de las escalinatas del Iron Man) }\end{array}$ \\
\hline$\underline{\text { PUNTO }}$ & LUGAR MCD \\
\hline 1 & Calle atrás de los restaurantes que da a la UPC \\
\hline 2 & Entrada Principal \\
\hline
\end{tabular}

Parte importante de las dinámicas declaradas en los hotspots invisibles al MCD policial corresponden a delitos sexuales (violaciones heterosexuales, una violación homosexual, un acoso pedofílico y múltiples acosos sexuales, fundamentalmente). Esto hace pensar que existe una relación entre el tipo de delito y la pobre iniciativa de la víctima en denunciar ante

\footnotetext{
${ }^{38}$ NOTA: En amarillo se colocan los hotspots que coinciden entre los MCC y el MCD. En naranja los hotspots saturados por los MCC. En azul los lugares marcados en el MCD y no saturados por los MCC.
} 
la policía o la Fiscalía, cuando se trata de exponer aspectos íntimos. En el relato policial, de hecho, estos casos no habían sido suficientemente o nada identificados.

De manera contraria, aparecen hotspots denunciados que no aparecen en los MCC. Estos sitios corresponden específicamente a las salidas posteriores de los restaurantes del balneario, usualmente utilizados para descargar comida, pagar proveedores y sacar basura. Esto conlleva a pensar que los MCC no reflejaron la actividad delictiva en los comerciantes de estos sectores, porque corresponden a una dinámica diferente que, simplemente, no fue atendida durante la aplicación segmentada de los MCC. Se trataría de un conjunto de locales comerciales establecidos que ven en la denuncia policial un recurso necesario, habitual y más confiable, a diferencia de los visitantes, los comerciantes callejeros y residentes. La policía formaría parte del funcionamiento del negocio, así como de los requisitos de las aseguradoras.

\subsection{Resultados en términos de percepción de seguridad o sentimiento de inseguridad ${ }^{39}$ a partir de las entrevistas en los MCC}

En la primera fase (before) según la percepción de los informantes, se expresó inconformidad con respecto a la eficiencia por parte de los agentes policiales del sub-circuito, ya que decían que el patrullaje no era percibido como suficiente y eso hacía que los delincuentes aprovecharan para cometer hechosdelictuales en los micro-territorios investigados.

Otro punto consistió en que, cuando las personas eran victimizadas, no había una respuesta inmediata por parte de los agentes policiales, haciendo a las víctimas abstenerse de denunciar:piensan queno tendrá ningún sentido la acción pues no se hará nada al respecto, reacción asociable al sentimiento de inseguridad y vulnerabilidad por causa de la ausencia de la función policial. Adicionalmente, la población muestra con preocupación la desestimación por parte de la Policía Nacional a ciertos delitos catalogados como menos importantes (robo de celulares, acoso en vías públicas, hurto), dando como resultado que las personas se abstengan a denunciarlos. Otra de las causales expresadas para inhibir la denuncia es que los procesos judiciales son muy lentos, por motivo del re-direccionamiento de denuncias receptadas por parte de las unidades policiales comunitarias (UPC) enviadas hacia la Fiscalía General del Estado. Asimismo, a pesar de la existencia de la Defensoría Pública Gratuita, estos procesos llegan a ser muy costosos al tener el interesado que desplazarse de un lugar a otro y al asumir pagos de costas procesales.

En la segunda fase (after), con la implementación de cambio de estrategia, se pudo observar que la percepción de la acción de la policía nacional había mejorado. Si bien el sentimiento de seguridad no se muestra como pleno, los usuarios del espacio demuestran mayor

\footnotetext{
${ }^{39}$ A partir de Lola Aniyar de Castro el concepto de sentimiento de inseguridad se separa del concepto de miedo, por cuanto el primero es normal, pues forma parte del stock simbólico natural del sistema penal, mientras tanto, el segundo constituye una amenaza a la ciudadanía, así como una herramienta de control. BISTAGNINO (2012), passim.
} 


\section{Polít. Crim. Vol. 15, № 30 (Diciembre 2020), Art. 11, pp. 840- [http://politcrim.com/wp-content/uploads/2020/12/Vol15N30A11.pdf]}

tranquilidad y debaten con menos profusión los aspectos procedimentales que inhiben la acción de denuncia, como si fuesen menos importantes.

Estimamos que este claro cambio actitudinal responde a la naturaleza misma de las estrategias de prevención. El usuario no debate acerca de los problemas que enfrenta para superar las consecuencias del delito y su propia inseguridad, sino que secundariza el problema de la seguridad en su totalidad. Ante la reducción del sentimiento de inseguridad, el usuario no necesariamente mejora su percepción de los procedimientos institucionales, sino que les otorga menor preocupación o importancia. Así, los MCC, más sensibles a una lectura del espacio ordenada por aspectos de la estabilidad emocional, cumplen mejor su rol en la lectura del sentimiento de inseguridad. Así lo explica Rut Loor, desde su experticia en el área de la neurociencia, acerca de las ventajas que proveen los MCC:

"Aparentemente, los reportes policiales y denuncias de delitos recibidos a través de las receptorías de denuncias, reflejarían lo que podría estar ocurriendo en cada espacio geográfico del territorio administrado. Sin embargo, estaríamos obteniendo información referente solo a las víctimas que se decidieron informar sobre un hecho que les produjo una afectación, dejando por fuera una cantidad mucho mayor de hechos y condiciones de la comisión de la infracción. Variables densas y complejas como miedo a retaliación, oportunidad de redelinquir, exposición de la intimidad, desconfianza institucional, dificultad de acceso a las receptorías, interés policial en reducir las cifras de denuncias, burocracias aparatosas, entre tantas otras razones, pesan sobre la capacidad de la denuncia administrativa en proveer información fiable. Sin embargo, son, precisamente, la denuncia y el reporte policial, las fuentes desde donde se definen mayormente las estrategias derivadas de los análisis delictivos". ${ }^{40}$

\subsection{Comparación de actividad delictiva before/after según denuncias administrativas}

De manera puntual, el sistema de geo-referenciación de la Policía Nacional del Ecuador, el Sistema David, presenta, para fines de la investigación, la suma de las denuncias administrativas y reportes policiales para la Playa de Murciélago en los casos de delitos del Cuadro de Mando Integral, los cuales representan los delitos de robo a domicilios, robo a embarcaciones de espacios acuáticos, robo de bienes accesorios y autopartes de vehículos, robo a personas y hurto. La fuente estadística también provee información sobre insolvencia fraudulenta, la cual no fue tratado por los MCC. Estos fueron los resultados:

\footnotetext{
${ }^{40}$ LOOR et al. (2019), passim.
} 
CASTRO, Daniel; PIHUAVE, Pedro; PARRALES, Rosa; RAMÍREZ, Leticia; KARLO, Jean: "El mapa de las víctimas. Pertinencia de los mapas cognitivos compuestos en el análisis de la situación delictual a partir de un pequeño territorio"

Figura 7. Comparativo de delitos no sexuales en Playa Murciélago para el periodo antes y después de las políticas implementadas (DAID, 2019)

\begin{tabular}{|c|c|c|c|c|c|}
\hline \multicolumn{5}{|c|}{ Playa Murciélago } \\
\hline DELITO & $\begin{array}{c}1 \text { de MAY al } \\
31 \text { de DIC } \\
2017\end{array}$ & $\begin{array}{c}1 \text { de MAY al } \\
31 \text { de DIC } \\
2018\end{array}$ & $\begin{array}{c}\text { Variación } \\
\text { Porcentual }\end{array}$ & $\begin{array}{c}\text { Variación } \\
\text { Absoluta }\end{array}$ & $\begin{array}{c}\text { Peso } \\
\%\end{array}$ \\
\hline $\begin{array}{c}\text { Robo a } \\
\text { domicilios }\end{array}$ & 1 & 1 & $0 \%$ & 0 & $20 \%$ \\
\hline $\begin{array}{c}\text { Robo a } \\
\text { embarcaciones } \\
\text { de espacios } \\
\text { acuáticos }\end{array}$ & 1 & 0 & $-100 \%$ & -1 & $0 \%$ \\
\hline $\begin{array}{c}\text { Robo de } \\
\text { bienes, } \\
\text { accesorios y } \\
\text { autopartes de } \\
\text { vehículos }\end{array}$ & 2 & 1 & $-50 \%$ & -1 & $20 \%$ \\
\hline $\begin{array}{c}\text { Insolvencia } \\
\text { fraudulenta }\end{array}$ & 2 & 0 & $-100 \%$ & -7 & $0 \%$ \\
\hline $\begin{array}{c}\text { Robo a } \\
\text { personas }\end{array}$ & 6 & 3 & $-50 \%$ & -3 & $60 \%$ \\
\hline $\begin{array}{c}\text { Hurto } \\
\text { Total }\end{array}$ & 19 & 0 & & & \\
\hline
\end{tabular}


En términos de evolución por año, la curva muestra estos resultados:

Figura 8. Comparativo de delitos no sexuales en Playa Murciélago antes y después de las políticas implementadas, desde los periodos de medición (DAID, 2019)

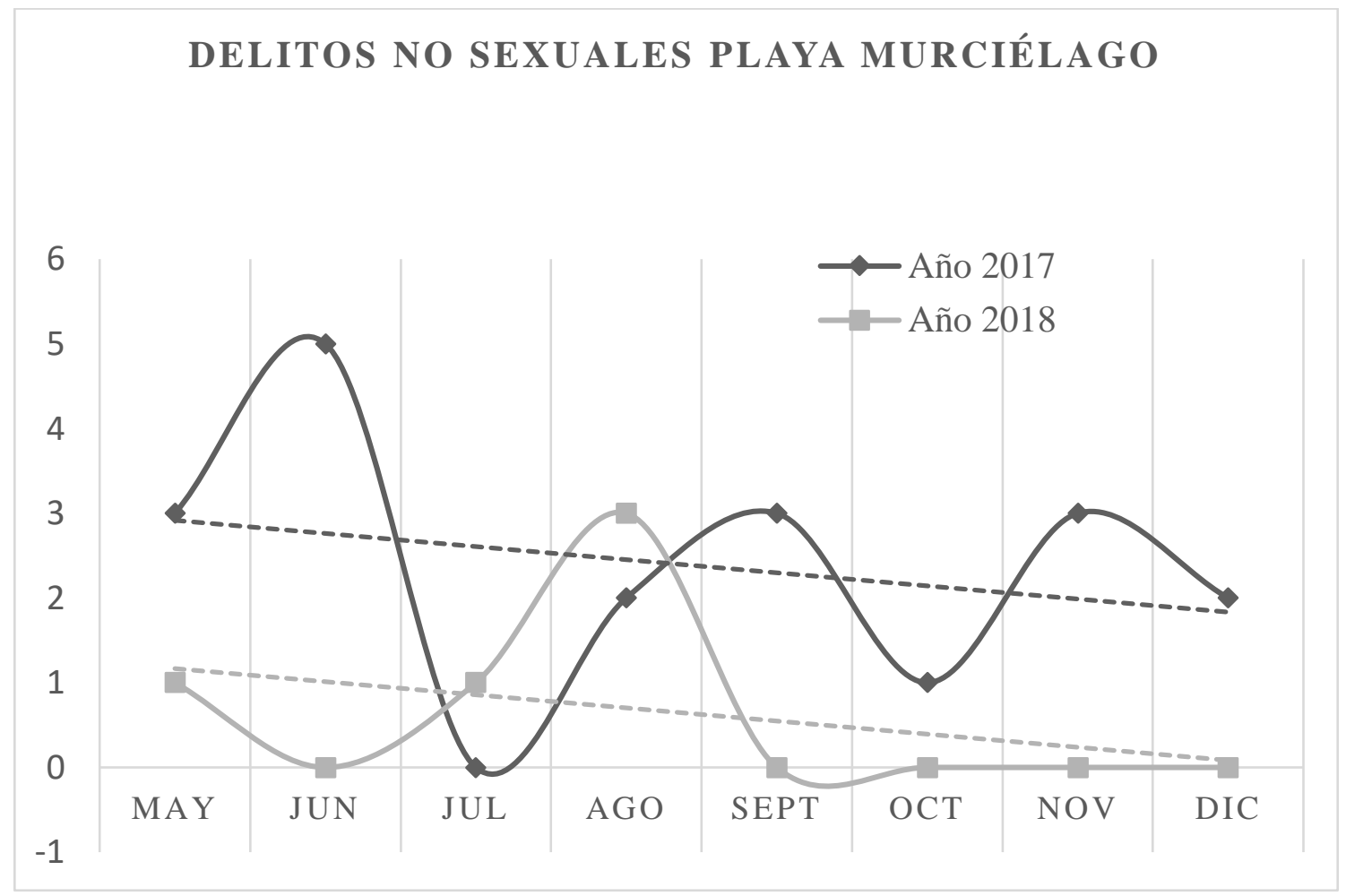

Del mismo modo, la Fiscalía General del Estado presenta la evolución estadística de los delitos sexuales que, por su naturaleza, son guardadas con criterios de confidencialidad en el despacho indicado. En este caso se comparan los años completos correspondientes a la aplicación de las políticas, con la excepción del 2019. Los delitos sexuales medidos para el 2019 no completan el período de un año entero al momento de este estudio, pero se han dejado pues evidencian, en una simple proyección aritmética, que los resultados siguen mejorando a la luz de la persistencia de las políticas criminales iniciadas en la primera mitad del 2018: 
Figura 9. Comparativo de delitos sexuales en Playa Murciélago para los años antes y después de las políticas implementadas (FGE, 2019)

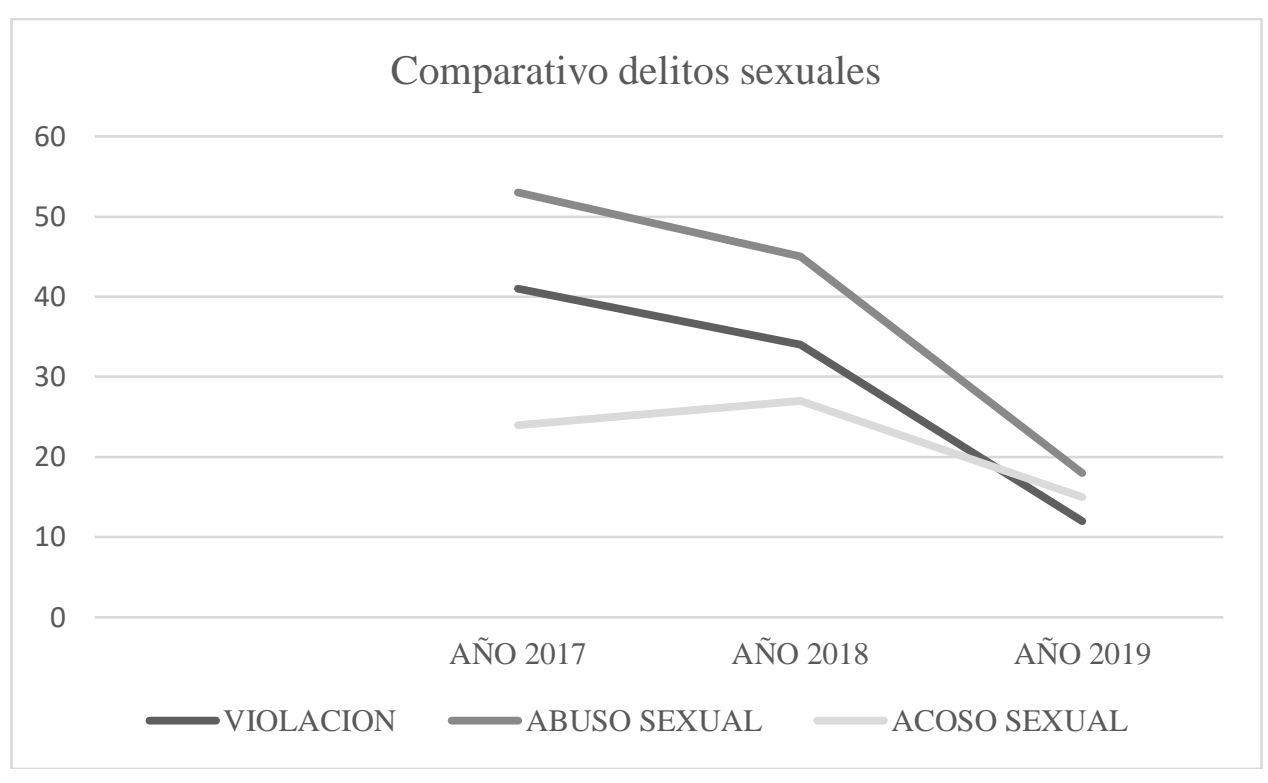

Como puede observarse, en casi todas las modalidades, es palpable un descenso de la actividad delictiva medida por denuncias. Siendo éstas las fuentes tradicionales de medición del delito, y que el comportamiento es común de manera persistente en casi todas las modalidades cuando se comparan por años, es posible considerar que este descenso representa un descenso en la comisión real de los delitos en el territorio, luego de la implementación de las medidas policiales diseñadas con los criterios de los MCC.

\section{Conclusiones}

En conclusión, este artículo hace evidente que los mapas cognitivos compuestos (MCC) son un instrumento criminométrico pertinente en un sub-circuito catalogado como de alta conflictividad.

Los MCC actúan como suplemento a las denuncias administrativas, las denuncias recolectadas por los agentes policiales, la propia experiencia en campo del policía, así como las encuestas de victimización, ya que abordan el diagnóstico mediante estrategias metodológicamente muy diferentes y, por tanto, de mayor profundidad. El carácter cuanticualitativo del instrumento, que equilibra la interpretación etnográfica con la saturación estadística, permite revelar dinámicas, oportunidades y situaciones delictivas susceptibles de crear políticas criminales más efectivas, que las puedan desprenderse de los MCD, las encuestas de victimización y la denuncia policial.

Por la naturaleza de su trabajo (patrullaje, recepción de denuncias, persecución de casos, básicamente), los agentes policiales solo pueden obtener resultados sobre los datos más generales de ciertos delitos, mientras que las víctimas y testigos, mediante saturaciones y triangulación, pueden proveer información valiosa desde otros puntos de vista más 
específicos a la dinámica delictiva del territorio, básicamente, por el hecho de haber tenido una experiencia delictual a profundidad, aunque sean individualmente inconscientes de su fenomenología sociológica.

En otras palabras, los MCC rescatan el ángulo de la víctima desde una estrategia cuanticualitativa, lo que permite visibilizar procesos generales, dinámicas y patrones en pequeños territorios, sirviendo de apoyo eficiente para los organismos de seguridad.

La policía de proximidad (UPC) se beneficia de utilizar los MCC para acercarse a los problemas delictuales de la comunidad y así poder brindar seguridad ciudadana y jurídica, creando nuevas estrategias para mejorar su actividad laboral y lograr prevenir hechos delictuales. Ya es incluso estimable su asociación con la reducción del delito en varios territorios, como el analizado en esta investigación. ${ }^{41} \mathrm{Sin}$ embargo, se requieren de investigaciones más a profundidad sobre el before/after para determinar esto con certeza.

Finalmente, los MCC dan a conocer la dinámica delictiva de los emprendedores delictuales desde una visión mucho más integral de factores macroeconómicos, familia, defensibilidad, eficiencia del servicio policial y otros factores complejos. Otorgan, por ello, una visión integrada de factores de oportunidad y situación, y son susceptibles de triangulación fuentes para confirmar la veracidad de la información. Por su naturaleza, no sucumben ante la tentación de tomar por cierta la información de un informante aislado, pues usa el sistema de saturaciones de la grounded theory, la cual solo establece la existencia de hechos sociales cuando éstos tienen un nivel aceptable de recurrencias. Adicionalmente, prepara la información para ser contrastada con otros territorios, generando patrones susceptibles de políticas públicas y criminales a nivel cantonal, provincial y nacional.

La dinámica delictiva que se obtiene de los MCC muestra la forma o manera en que actúan los victimarios para poder ejecutar un crimen de manera integrada con sus oportunidades para delinquir y con las situaciones que son particulares al territorio y la dinámica social, a partir del ángulo de la víctima. Por ello, reconocen el hecho delictivo desde dentro de la geometría del delito, activando dispositivos mnémicos de mucha mayor calidad que los que puedan estar filtrados por la verbalización émica o el oportunismo asociado al proceso de la denuncia. ${ }^{42}$

En relación al relato policial, obtenido del testimonio del comandante a cargo, los MCC confirmaron los sitios peligrosos que ya se habían saturado en los instrumentos aplicados anteriormente, pero muestra bloqueos en el relato sobre puntos menos importantes o sin peligro. Este es el caso del territorio que se extiende desde la "casa de los surfistas" hasta la "zona rocosa" del noreste, así como la "zona rocosa" del suroeste, los cuales, a diferencia del relato policial, saturaron abundantemente. Es posible que esto tenga que ver con la naturaleza sexual de los delitos que mayormente corresponden a estos hotspots, mostrando con ello que el instrumento accede a información relevante que la víctima no desea hacer pública por razones de intimidad y/o privacidad y que, de otra manera, se perdería.

\footnotetext{
${ }^{41}$ BARCIA et al. (2018), passim.

${ }^{42}$ LOOR et al. (2019), passim.
} 
A partir del cambio de comandancia de la UPC en febrero del 2018, la policía incluyó un nuevo set de estrategias de tipo preventivas sobre los hotspots que coincidieron entre los MCC y el relato policial. Por ello, además de las ventajas metodológicas descritas, el set tuvo un relativo impacto positivo en la reducción y/o percepción del delito para el territorio, medible por denuncias administrativas y reportes policiales antes y después de la implementación de las políticas asociables al instrumento, así como muestra evidencias en el mejoramiento de la percepción de inseguridad a partir de los mismos MCC.

Todo ello hace pensar que la justeza diagnóstica del instrumento analizado se muestra como es una fuente confiable para el diseño eficiente de políticas criminales de prevención en el territorio. 


\section{Bibliografía citada}

BARCIA, Sonia, RAMÍREZ, Leticia; PARRALES, Rosa. (2018): "Efectos de dinámicas macroeconómicas en la idea de situación delictiva: el caso de Playa Murciélago a partir de Mapas Cognitivos Compuestos (MCC)”, en: Revista Espacio Abierto. Cuaderno Venezolano de Sociología (Vol. 27, $\mathrm{n}^{\mathrm{o}}$ 4). Disponible en: https://dialnet.unirioja.es/servlet/articulo?codigo=6971594 [visitado el 17/12/2020].

BISTAGNINO, Paula (2012): Lola Aniyar de Castro, precursora de la criminología en América Latina, visitó la UNSAM, en:Cosecha Roja. Disponible en: http://cosecharoja.org/lola-aniyar-de-castro-precursora-de-la-criminologia-enamerica-latina-visito-la-unsam/ [visitado el 17/12/2020].

BRANTINGHAM Patricia; BRANTINGHAM, Paul (1993): Environment, Routine, and Situation: Toward a Pattern Theory of Crime: Advances in Criminological Theory (Michigan, Sage Publications).

BRODEUR, Jean (2003): Les visages de la police. (Les presses de l'Université de Montreal, Montreal).

CASTRO-ANIYAR, Daniel, (2019a): "Boy, do not touch that plug: The table of drug use in Ecuador in the light of critical criminology" en: Revista Utopía y Praxis Latinoamericana (No 84, Vol. 24). Disponible en: https://zenodo.org/record/3344844\#.XZYujEb0nIU [visitado el 17/12/2020].

CASTRO-ANIYAR, Daniel (2019b): "Paintings for a Crime": Composed Cognitive Maps for Measuring Crime Situation", en: Journal of Victimology and Victim Justice (National Law University Delhi, Delhi,SAGE), pp. 1-23.

CASTRO-ANIYAR, Daniel (2018): “Los Mapas Cognitivos Compuestos. Una respuesta a problemas generales de medición del delito", en: CASTRO-ANIYAR, Daniel (Ed.) Leccionario de Derecho Fundamental y Criminología (Manta, Ediciones Uleam), pp. 552-595.

CASTRO-ANIYAR, Daniel (2015): Diagnóstico y diseño de un programa de Seguridad Ciudadana para el Distrito Metropolitano de Quito, local, interagencial, participativo, integral, con estrategias de visibilización, inclusión y respeto de los Derechos Humano, en: Programa Prometeo (Quito, Ministerio del Interior, Secretaría Nacional de Ciencia y Tecnología). Disponible en: http://repositorio.educacionsuperior.gob.ec/handle/28000/3558/browse?type=author \&order=ASC\&rpp=20\&value=Castro+Aniyar\%2C+Daniel [visitado el 17/12/2020].

CASTRO-ANIYAR, Daniel, JÁCOME, JuanCarlo, MANCERO, Jorge, (2015): "Seguridad ciudadana en Ecuador: Política ministerial y evaluación de impacto, años 20102014”, en: Revista Nova Criminis (No. 9) p. 111-148

CASTRO-ANIYAR, Daniel, JÁCOME, Juan Carlos (2017a). "El trilema VDS: Medición del delito con la base en la situación delictiva”, en: Revista de Criminología y Derecho Penal (Buenos Aires, Thomson Reuters,La Ley).

CASTRO-ANIYAR, Daniel (2017b): "Problemas Políticos de Medición del delito a la luz del Enfoque por Territorio, oportunidad y situación”, en: Revista Nova. Criminis (Num. 13). 
CENTER FOR PROBLEM- ORIENTED POLICING (2018): Center for Problem- Oriented Policing. (NY, University at Albany State, University of New York). Disponible en: http://www.popcenter.org/about/?p=whatiscpop [visitado el 17/12/2020].

DAMMERT, Lucía; SALAZAR, Felipe; MONTT, Cristóbal; GONZÁLEZ, Pablo (2010): Crimen e Inseguridad. Indicadores para las Américas. Disponible en: https://www.vanderbilt.edu/lapop/news/FLACSO_on_crime.pdf [visitado el $17 / 12 / 2020]$.

DAID (2019): Estadísticas del Cuadro de Mando Integral. (Quito, Sistema David. Departamento de Análisis e Información del Delito. Policia Nacional).

DAID, (2016): Análisis estadístico asesinatos y homicidios nivel nacional (Quito, Documento interno. Ministerio del Interior).

DE ALBUQUERQUE, Klaus (1984); “A Comparative Analysis of Violent Crime in the Caribbean", en: Social and Economic Studies (33(3)), pp. 93-142. Disponible en: https://www.jstor.org/stable/27862082?seq=1 [visitado el 17/12/2020].

DIJK, Janvan; KESTEREN, John van, SMIT, P. (2007): Criminal Victimisation in International Perspective. Key findings from the 2004-2005 ICVS and EU ICS (México, Justitie, Tilburg University. UNICRI, UNDC. BJU). Disponible en: http://www.unicri.eu/services/library_documentation/publications/icvs/publications/ ICVS2004_05report.pdf [visitado el 17/12/2020].

FERRET, Jean (2004): “¿Evaluar la llamada policía de proximidad? certezas e incertidumbre obtenidas en las experiencias francesas", en: Revista Catalana de Seguretat Pública (Paris, No.12). $\quad$ pp. $180 . \quad$ Disponible en: https://www.raco.cat/index.php/RCSP/article/view/131533/181351 [visitado el $17 / 12 / 2020]$.

FGE (2019): Bases estadísticas Delitoscopio (Manta, Fiscalía General del Estado).

FUNDACIÓN PAZ CIUDADANA (2012): Análisis delictual: técnicas y metodologías para la reducción del delito. Disponible en: http://www.pazciudadana.cl/wpcontent/uploads/2012/07/analisis-delictual-tecnicas_2012.pdf $\quad$ [visitado el $17 / 12 / 2020]$.

FRÜHLING, Hugo, (2003): Policía Comunitaria y Reforma Policial en América Latina: ¿Cuál es su impacto? Experiencias y temáticas. Disponible en: https://www.cesc.uchile.cl/publicaciones/op_01_policiacomunitaria.pdf_[visitado el 17/12/2020].

KITCHIN, Robert, (1996): "Increasing the integrity of cognitive mapping research: appraising conceptual schemata of environment-behavior interaction" en: Human Geography $\quad(20,1)$ Disponible http://journals.sagepub.com/doi/pdf/10.1177/030913259602000104 [visitado el $17 / 12 / 2020]$.

KONECKI, K.T. (2011): "Visual Grounded Theory: A Methodological Outline and Examples from Empirical Work" en: Rad znanstveni Izvorni (Primljeno: 2. 3). Disponible en: https://webcache.googleusercontent.com/search?q=cache:qbPnd1HB8RoJ:https://hr cak.srce.hr/file/106256+\&cd=12\&hl=es\&ct=clnk\&gl=ec [visitado el 17/12/2020].

LYNCH, Kevin (1960): The Image of the City(Barcelona, Editorial Gustavo Gili, SL). 
LOOR, Rut, MENDOZA, Francisco, MIELES, Erika, ROCAFUERTE, Miguel (2019): "Esto me recuerda...". Aspectos de la pertinencia política y neuro-psicológica de los Mapas Cognitivos Compuestos en el análisis del delito", en: Revista Utopía y Praxis Latinoamericana (Año 24 No. EXTRA 2). Disponible en: https://zenodo.org/record/3344856\#.XZYu-Eb0nIU [visitado el 17/12/2020].

MINISTERIO DEL INTERIOR DE ECUADOR (2018): Áreas de concentración de delincuencia de delitos contra el derecho a la propiedad. Del 01 de Enero 2016 al 17 de Marzo 2018. Estudios de incidencia delictiva 2016-2018. (Policía Nacional. DAID).

MINISTERIO DEL INTERIOR DE ECUADOR (2013): Policía comunitaria modelo de gestión. Manual de policía comunitaria (Quito, POLCO), pp. 135

NEWMAN, Oscar (1996): Creating Defensible Space (New Jersey, U.S., Institute for Community Design Analysis, Department of Housing and Urban Development Office of Policy Development and Research), pp. 126.

PAULSEN, Derek, Bair, Sean. \& Helms, Dan, (2012): Tactical Crime Analysis: Research and Investigation (Boca Ratón, London, New York, Taylor \& Francis Group, CRC Press).

Policía Nacional (2012): Modelo de Desconcentración de los Servicios que Brinda la Policía Nacional Del Ecuador. (Quito, Documento interno de formación, Policía Nacional)

Policía Nacional (2012a): Nuevo Modelo de Gestión de la Policía Nacional (Dirección Nacional de Educación. Departamento de Derechos Humanos. Documento Interno de formación policial)

POLCO (2014): Matriz Productividad POLCO-Ministerio (Quito, Documento interno. Elaboración: Econ. Ileana Pozo. POLCO)..

PONTÓN, Daniel (2009): Policía Comunitaria y Cambio Institucional en el Ecuador. Disponible

en: http://www.flacsoandes.edu.ec/relasedor/images/publicaciones/pdf/policia_comunit aria_cambio_institucional_en_el_ecuador_2.pdf [visitado el 17/12/2020].

ROUTLEDGE, Paul, (2000): "Consuming Goa: Tourist Site as Dispensable Space", en :Economic and Political Weekly(35(30)), pp. 2647-2656. Disponible en: https://www.jstor.org/stable/4409533?seq=1 [visitado el 17/12/2020].

Secretaría Nacional de Planificación y Desarrollo (2018): SENPLADES. Disponible en: http://www.planificacion.gob.ec/ [visitado el 17/12/2020].

Secretaría Nacional de Planificación y Desarrollo (2012): ¿Qué son las zonas, distritos y circuitos?. (Quito, SENPLADES), pp. 17. Disponible en: http://www.planificacion.gob.ec/wpcontent/uploads/downloads/2012/10/Folleto_Popular_DyC_24-10-2012.pdf [visitado el 17/12/2020].

SHERMAN, Lawrence (1996): "Policing for crime prevention". Disponible en: https://www.ncjrs.gov/works/chapter8.htm [visitado el 17/12/2020]. 